\title{
Arqueología del futuro en el barrio El Raval de Barcelona. A propósito de tres inercias del urbanismo tecnocrático y sus efectos indeseables
}

Miquel Fernández ${ }^{1} \mid$ Maribel Cadenas ${ }^{2}$

Recibido: 08-12-2020 | en su versión final: 15-02-2021

Resumen

\begin{abstract}
Este artículo es el resultado de nuestro esfuerzo analítico para comprender cómo se han pensado y practicado intervenciones urbanísticas, extremadamente drásticas, contra el barrio El Raval de Barcelona en períodos formalmente democráticos. Lo que consideramos original de nuestra propuesta analítica es la identificación de una suerte de doxa tecnocrática que habría impregnado el urbanismo -también el barcelonés- desde sus inicios, y que acabará caracterizando el aclamado tanto como discutido "Modelo Barcelona". La metodología utilizada proviene de la antropología histórica y de la sociología urbana. Nuestro prisma teórico entrecruza perspectivas historiográficas como la biopolítica, sociológicas como la crítica a la ingeniería social y urbanísticas como la reconfiguración del espacio público. Se sostiene aquí que el urbanismo racionalista habría abordado el complejo arte de vivir en sociedad desde fórmulas cartesianas, cómplices en gran medida de la reificación característica de disciplinas positivistas. Consideramos que esta forma de concebir el urbanismo se ha nutrido de presupuestos conceptuales epistemológicamente inconsistentes, simplificadores y, a menudo, autoritarios. La última parte del artículo identifica tres de las inercias sociales que vendrían generadas o impulsadas por la tecnocracia -no solo urbanística: La tendencia obsesiva hacia la normalización y sus perversos efectos; las contradicciones entre las "soluciones" y los "problemas sociales" que se quieren gestionar y, finalmente, la inclinación a considerar la calle como una suerte de campo de batalla y, por tanto, el hogar como un refugio.
\end{abstract}

Palabras clave: movimiento moderno; biopolítica; ingeniería social; normalización social

Citación

Fernández, M. y Cadenas, M. (2021). Arqueología del futuro en el barrio El Raval de Barcelona. A propósito de tres inercias del urbanismo tecnocrático y sus efectos indeseables, ACE: Architecture, City and Environment, 15(45), 10311. DOI http://dx.doi.org/10.5821/ace.15.45.10311

\section{Archeology of the Future in El Raval Neighborhood of Barcelona. About Three Inertias of Technocratic Urbanism and their Undesirable Effects}

Abstract

\begin{abstract}
This article is the result of our analytical effort to understand how extremely drastic urban interventions have been thought and practiced against the El Raval neighborhood of Barcelona in formally democratic periods. What we consider original of our analytical proposal is the identification of a kind of technocratic doxa that would have permeated urbanism -also Barcelona urbanism- from its beginnings and that will end up characterizing the acclaimed as well as the controversial "Barcelona Model". The methodology used comes from historical anthropology and urban sociology. Our theoretical prism intersects historiographic perspectives such as biopolitics, sociological perspectives such as criticism of social engineering and urban planning perspectives such as the reconfiguration of public space. It is argued here that rationalist urbanism would have approached the complex art of living in society from Cartesian formulas, accomplices to a large extent of the reification characteristic of positivist disciplines. We consider that this way of conceiving urbanism has been nourished by epistemologically inconsistent, simplifying and often authoritarian conceptual assumptions. The last part of the article identifies three of the social inertias that would be generated or driven by technocracy - not just urban planning technocracy: The obsessive tendency towards normalization and its perverse effects; the contradictions between the "solutions" and the "social problems" to be managed; and finally, the inclination to consider the street as a kind of battlefield and, therefore, the home as a refuge.
\end{abstract}

Keywords: modern movement; biopolitics; social engineering; social normalization

${ }^{1}$ Dr. Antropología Social, Departamento de Sociología, UAB (ORCID ID: 0000-0001-7982-7833; ResearcherID: O-6509-2019; Scopus Author ID: 56081744400), ${ }^{2}$ Arquitecta, Grup de Recerca en Antropologia de l'Arquitectura (GRANAR) de l'Institut Català d'Antropologia. Correo de contacto: miquel.fernandez@uab.cat

ACE, 15 (4.5) CC BY-ND 3.0 ES | UPC Barcelona, España | Arqueología del futuro en el barrio de El Raval de Barcelona. A propósito de tres inercias del urbanismo tecnocrático y sus efectos indeseables. DOI http://dx.doi.org/10.5821/ace.15.45.10311 


\section{Introducción: identificando la tecnocracia en el urbanismo barcelonés}

Este artículo es el resultado de nuestro esfuerzo analítico para comprender cómo se han pensado y practicado intervenciones urbanísticas extremadamente drásticas contra el barrio El Raval de Barcelona en períodos formalmente democráticos. Estos proyectos se iniciaron en 1988, con la demolición de la Illa Sant Ramon, y se dan por finalizados en 2012 con la inauguración de la Filmoteca Nacional de Catalunya en el nuevo epicentro del mítico y dinámico "Barrio Chino", la Plaça Salvador Seguí, también conocida como llla Robador.

En nuestra indagación hemos querido identificar los trazos tecnocráticos del urbanismo decimonónico que afectarán tanto el Pla Nova Barcelona (o Pla Macià) de 1932 como los desarrollados con la reanudación democrática. Para ello desentramaremos los presupuestos urbanístico-técnicos y político-morales anclados en el Pla Macià. Queremos identificar desde una perspectiva crítica, las lealtades y los regateos -como luego veremos- de las últimas intervenciones en El Raval respecto el gran proyecto racionalista diseñado por el Grup d'Arquitectes i Tècnics Catalans per al Progrés de l'Arquitectura Contemporània (GATCPAC) y asesorado por el arquitecto urbanista más destacado y controvertido del momento, Le Corbusier. Hemos querido descubrir entonces de qué manera la prevalencia de la racionalidad instrumental, característica del Movimiento Moderno y contraria a la razón crítica (Heynen, 1999), han posibilitado concebir e implementar operaciones extremadamente contundentes contra poblaciones sempiternamente vilipendiadas (Aisa y Vidal, 2006; von Heeren, 2002, entre muchos otros; Pascual, 1981; Vázquez-Montalbán, 2002; Villar, 1996).

Dicho esto, lo que consideramos original de nuestra propuesta analítica es la identificación de una suerte de doxa tecnocrática que habría impregnado el urbanismo -también el barcelonés- desde sus inicios, y que acabará caracterizando el aclamado tanto como discutido "Modelo Barcelona". La metodología empleada se basa en el análisis de las propuestas de intervención del GATCPAC y su influencia en las llevadas a cabo en El Raval desde 1988 hasta 2012. Para ello se ha realizado trabajo de archivo, historiográfico y etnográfico, este último, en el ámbito de la última gran intervención, la calle d'En Robador. Nuestro prisma teórico entrecruza perspectivas historiográficas como la biopolítica, sociológicas como la crítica a la ingeniería social y urbanísticas como la reconfiguración del espacio público. El método analítico empleado es la antropología histórica (Stolcke, 2015), y surge de la distinción propuesta por Claude Lévi-Strauss entre la antropología y la historiografía (1960). Según el etnólogo francés, si la historia se ocupaba de recoger los elementos conscientes de la acción humana, la antropología haría una tarea análoga pero reconstruyendo lo que Marcel Mauss define como las categorías inconscientes (1936) o lo que Radcliffe-Brown identifica como las estructuras generales y persistentes de toda sociedad humana (1935). Dicho de otro modo, si el historiador organiza sus datos en relación con las experiencias conscientes de la vida social, el antropólogo busca la explicación de los acontecimientos en las condiciones inconscientes.

Aclarado esto, nuestra hipótesis principal se ancla en la crítica a la idea de progreso como fin en sí mismo y a la tecnocracia como forma de gobierno que le da forma. Además, supone que el epítome de este urbanismo racionalista se encuentra, primero y por definición, en el Movimiento Moderno y llegaría hasta la Smart City como fórmula en la que son los propios algoritmos los que pueden determinar el diseño y la gestión de la urbe.

\footnotetext{
${ }^{1}$ Concepto con el que el sociólogo Pierre Bourdieu juega con los dos sentidos de la palabra: la doxa, el sentido común, implica siempre un orden de dominación -un sentido impuesto- y conlleva una aceptación del orden social como algo evidente e incuestionable. En el registro de la doxa no hace falta decir que las cosas son como son. Frente a él está la heterodoxia, discurso que impugna la coincidencia de evidencia y realidad, y que cuestiona las evidencias y la ortodoxia -el discurso que, frente a la heterodoxia, reafirma que lo evidente es real. Los dominantes tienen interés en la doxa, es decir, en la evidencia incuestionada que les mantiene en la posición dominante (Bourdieu, 2008, pp. 27-28).
}

ACE, 15 (4.5) CC BY-ND 3.0 ES | UPC Barcelona, España|Arqueología del futuro en el barrio de El Raval de Barcelona. A propósito de tres inercias del urbanismo tecnocrático y sus efectos indeseables. DOI: http://dx.doi.org/10.5821/ace.15.45.10311 
El artículo empieza entonces con una aproximación sociológica al concepto de tecnocracia. Se sostiene aquí que el urbanismo racionalista habría abordado el complejo arte de vivir en sociedad desde fórmulas cartesianas, cómplices en gran medida de la reificación característica de disciplinas positivistas. Consideramos que esta forma de concebir el urbanismo se ha nutrido de presupuestos conceptuales epistemológicamente inconsistentes, simplificadores y a menudo autoritarios. El análisis somero del Plan de Reforma y Ensanche de Ildefons Cerdà permite reconocer su legado tecnocrático en el Movimiento Moderno y su diseño del Pla Macià.

Seguidamente haremos una reflexión sobre los principios de este urbanismo en Barcelona y, concretamente, sobre El Raval. Aquí señalaremos los principios maquinales del Pla Maciá y, posteriormente, criticaremos la alabanza selectiva del mismo como legitimadora de las amplias destrucciones en El Raval. Para luego y, finalmente, intentar establecer hasta qué punto la propuesta de Smart City para las ciudades de hoy en día se puede considerar la máxima expresión del urbanismo tecnocrático y de sus efectos perversos.

La última parte identifica tres de las inercias sociales que habrían animado este urbanismo velado tras la fuerza de la razón y la eficiencia. Si en El Raval se han cronificado una serie de "problemas sociales", que ya habían sido identificado tanto en los trabajos de Ildefons Cerdà (1978 [1867]) como en los del GATCPAC $(1932,1937)$, es porque no se han advertido -o han devenido inconscientes- las tres inercias sociales ${ }^{2}$ con las que concluimos este texto: Primera, siguiendo las premisas de la biopolítica foucaultiana, la necesidad de "normalizar" El Raval habría comportado indefectiblemente la emergencia de espacios sociales y segmentos poblacionales "anormales" y, concretamente, en el caso de la España postfranquista, "peligrosos"3. El segundo conjunto de inercias lo encontramos siguiendo el rastro weberiano y a través de la mirada de Zygmunt Bauman. Este sociólogo desarrolla la crítica a la producción de "problemas sociales", paradójicamente definidos a raíz de la expansión de las "ingenierías sociales" para "solucionarlos". Y, finalmente, el análisis de Richard Sennett apunta una tercera inercia: el deterioro de la vida pública urbana como consecuencia de la "caída del hombre público". Este rechazo a la vida pública y sus nefastos efectos empezó a incubarse con la aceleración del individualismo y la sacralización de la vida doméstica.

\section{Trazos tecnocráticos en el urbanismo de El Raval de Barcelona}

Desde la filosofía de la historia, concebimos la tecnocracia como el último de los universos simbólicos y de sentido de nuestras sociedades contemporáneas. Se trataría de una suerte de nueva "religión tecnológica basada en el mito del progreso" (Campillo, 1999, p. 46). Este universo simbólico científicotecnológico permitiría dotar de sentido práctico y simbólico una nueva articulación de las tres relaciones básicas fundamentales: las políticas, las económicas y las doméstico-sexuales o reproductivas, en la sociedad capitalista global.

Este nuevo universo simbólico habría hecho concebible y practicable la destrucción de tejido urbano consolidado sin precedentes en Europa (Fig. 1), paradójicamente, en nombre del bien de la ciudad y del barrio intervenido (Fernández, 2012). Este nuevo paradigma -por decirlo a la manera de Thomas Kuhn (1971)- se abastece de la idea fuerza según la cual se pueden resolver los llamados "problemas

\footnotetext{
${ }^{2}$ Aun siendo un concepto usado rara vez por la sociología contemporánea, tiene sus valedores en autores clásicos como George Simmel, Émile Durkheim o Gabriel Tarde, entre otros. De una forma necesariamente simple, lo podemos definir aquí como tendencias sociales, generalmente inconscientes, que arrastran principios cognitivos y de sentido que impulsan la acción individual y colectiva, dando forma a una suerte de razón práctica.

${ }^{3}$ Nos referimos aquí a la Ley sobre peligrosidad y rehabilitación social que venía a substituir a la Ley de vagos y maleantes de 1931 de la República y que estuvo vigente durante todo el franquismo. La ley de Peligrosidad Social dirigida específicamente a perseguir a vagabundos, nómadas, pequeños delincuentes o expresiones públicas de homosexualidad o consumo de drogas.
}

ACE, 15 (4.5) CC BY-ND 3.0 ES | UPC Barcelona, España | Arqueología del futuro en el barrio de El Raval de Barcelona. A propósito de tres inercias del urbanismo tecnocrático y sus efectos indeseables. DOI http://dx.doi.org/10.5821/ace.15.45.10311 


\section{ACE Architecture, City and Environment}

E-ISSN 1886-480

sociales" mediante intervenciones científicas o en el caso que nos ocupa, urbanístico-arquitectónicas. Este "gobierno de los técnicos" se arroga la aparente neutralidad de la racionalidad instrumental para solucionar problemas humanos interviniendo científicamente sobre las formas de habitar, las prácticas urbanas y la construcción de la ciudad (Fernández, 2012).

Figura 1. Fragmento de una de las intervenciones en el Raval, Illa Robador

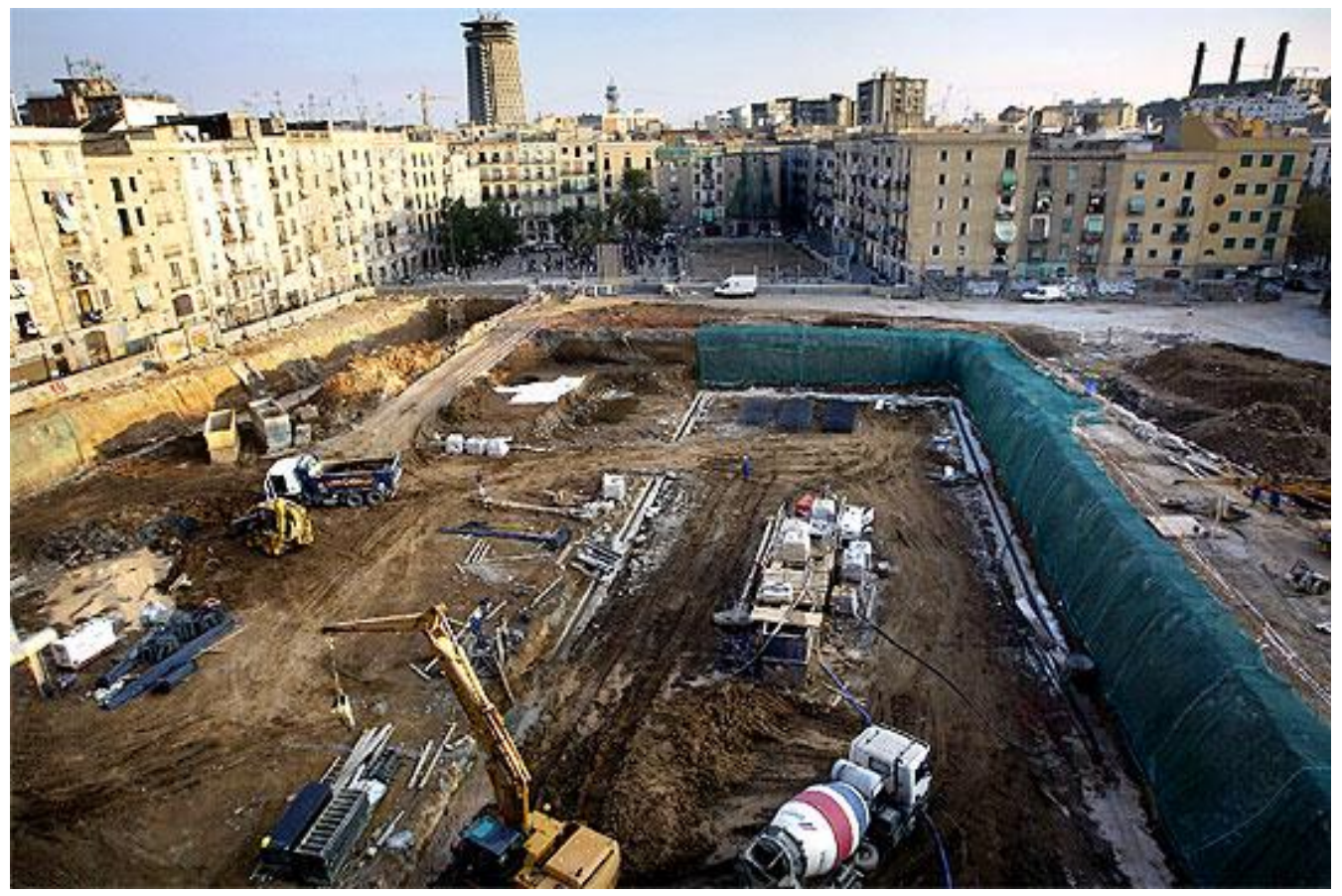

1'Autor: Vicens Giménez, 2008

La tecnocracia la podemos entender también como una forma gerencial de organizar las sociedades. Se trata de un principio vivo aún en nuestros días que quizás naciese con la modernidad, se desplegase con furor a mediados del s. XIX y con pudor, pero aún más categórico, en la segunda mitad del s. XX. Un principio, según el cual, las sociedades evolucionan siempre en una dirección única, implicando mejoras para el conjunto de la sociedad. El progreso o el "desarrollo" iría imperturbablemente en la dirección de mejorar las sociedades y hacerlas más ricas materialmente. Este supuesto tiene su crítica original en los trabajos de la escuela de Frankfurt y, especialmente, en su buque insignia La Dialéctica de la llustración (Adorno y Horkheimer, 2008 [1944]) que, a su vez, está fuertemente inspirado en las Tesis sobre la filosofía de la Historia de Walter Benjamin. Para el autor de Calle de sentido único (2015 [1928]), el progreso deja a su paso un rastro de ruinas que no queremos ver: "Hay un cuadro de Klee que se llama Angelus Novus. En él se representa a un ángel que parece como si estuviese a punto de alejarse de algo que le tiene pasmado. Sus ojos están desmesuradamente abiertos, la boca abierta y extendidas las alas. Y éste deberá ser el aspecto del ángel de la historia. Ha vuelto el rostro hacia el pasado. Donde a nosotros se nos manifiesta una cadena de acontecimientos, él ve una catástrofe única que amontona incansablemente ruina sobre ruina, arrojándolas a sus pies. Bien quisiera él detenerse, despertar a los muertos y recomponer lo despedazado. Pero desde el paraíso sopla un huracán que se ha enredado en sus alas y que es tan fuerte que el ángel ya no puede cerrarlas. Esta tempestad le empuja irresistiblemente hacia el futuro, al cual da la espalda, mientras que los montones de ruinas crecen ante él hasta el cielo. Ese huracán es lo que nosotros llamamos progreso." (Thesi IX, 2008 [1940], p 44)

ACE, 15 (4.5) CC BY-ND 3.0 ES | UPC Barcelona, España | Arqueología del futuro en el barrio de El Raval de Barcelona. A propósito de tres inercias del urbanismo tecnocrático y sus efectos indeseables. DOI: http://dx.doi.org/10.5821/ace.15.45.10311 
La ilusión tecnocrática propia de una lectura constreñida de la revolución Ilustrada, aterrizó en el urbanismo de la mano del Barón Von Haussman en París (Harvey, 2008) y de Ildefons Cerdà en Barcelona (Grau y López, 1988a; Guàrdia, 2009). Frecuentemente se oblitera que el urbanismo nació, junto con la policía, al calor de las innumerables insurrecciones urbanas que se extendieron por toda Europa durante la segunda mitad del s. XIX (Hall, 2002). En este sentido, Àngel Baixeras, responsable del Plan de Reforma Interior de Barcelona (1878)4, denunciará: "Aquellos centros, sobre ser malsanos por su estructura, son asimismo un peligro social, porque se utilizan siempre como baluarte seguro de cualquier motín y también prestan secreto a los garitos y al crimen." (Baixeras citado en VVAA, 2004, p. 199)

Para el caso barcelonés, valga también como ejemplo de estas intenciones la cita de Léon Jaussely, discípulo directo de Haussmann y autor del proyecto ganador (1903) para unir los pueblos del llano con el resto del Eixample y éste con la ciudad vieja, donde aclarará los objetivos de sus intervenciones en los abigarrados centros urbanos europeos: "Haremos una gran ciudad ideal, la ciudad industrial de nuestros sueños. Haremos una ciudad donde pueda explotar la nueva civilización de las democracias. Haremos científicamente los barrios obreros, para que puedan vivir con comodidad las multitudes disciplinadas." (Jaussely citado por Pijoan, 1905, p. 11.X)

Sobra decir aquí que, ni Haussman ni Cerdà se consideraron jamás revolucionarios. Su intención, proveniente de un progresismo ilustrado, era evitar estas insurrecciones mediante el establecimiento de formas urbanas redistributivas. Concretamente Cerdà, a diferencia de sus contemporáneos Marx y Engels, no contempla la revolución proletaria como una fatalidad. Su esfuerzo va a ir destinado a evitar la subversión violenta del orden social que considera innecesario para el progreso. Para Cerdà "las puertas del futuro no se abren con la llave de la revolución, sino con el miedo a la revolución." (Grau y López, 1988b, p. 181). Y es que, intención manifiesta o latente de estos urbanistas canónicos era conseguir que "la ciudad sea indefendible por sus habitantes" (Fraile, 2003, p. 181). Este urbanismo se iría institucionalizando y profesionalizando, respondiendo a estas nuevas necesidades de las nacientes sociedades industriales: el control del creciente número de habitantes -en su mayoría desarrapados- y su tendencia a concentrarse o a ser confinados en espacios abigarrados tanto como depauperados. Esta necesidad de control (Bergalli y Capel, 1990; Fraile, 1990; 2003) venía a complementar la demanda característica del capitalismo, esto es, el aumento de la velocidad de circulación de capital (Benévolo, 1993; Fraile, 2005).

\section{Arqueología del "Modelo Barcelona" desde el Pla Macià}

En Barcelona las primeras décadas del siglo XX marcarán un hito en el combate social en toda Europa. Las confrontaciones se cobrarán centenares de víctimas proletarias, también miembros del clero, empresarios y asesinos a sueldo de la patronal. Las victorias del lado obrero devendrán en mejoras laborales substanciales ${ }^{5}$. Del lado del poder instituido, se afianzará la reproducción clasista y patriarcal que desoye los primigenios objetivos emancipatorios de la Ilustración (Heynen, 1999): una mayor autonomía societal e individual para todas (Castoriadis, 1987).

Los obreros, altamente movilizados y organizados, representaban una amenaza para el orden burgués. El urbanismo -tal y como hizo con Haussman o Cerdà- debía venir al rescate. El encargado

\footnotetext{
${ }^{4}$ El plan de Baixeras de remodelación de la parte antigua de la ciudad recogía el proyecto de Cerdà de apertura de tres grandes vías, denominadas inicialmente A, B y C. El proyecto original se realizó parcialmente ya que sólo se construyó la vía A, rebautizada como Via Laietana.

${ }^{5}$ El pasado 2019 se celebró el centenario de la Vaga de la Canadenca, huelga organizada por el sindicato anarcosindicalista CNT (Confederación Nacional de Trabajadores) y que conseguiría, por primera vez en Europa -poco después de la extinta URSS-, la aprobación por ley de la jornada de 8 horas (Ealham, 2005; VVAA, 2004).
}

ACE, 15 (4.5) CC BY-ND 3.0 ES | UPC Barcelona, España | Arqueología del futuro en el barrio de El Raval de

Barcelona. A propósito de tres inercias del urbanismo tecnocrático y sus efectos indeseables. DOI http://dx.doi.org/10.5821/ace.15.45.10311 
no será otro que Le Corbusier. El arquitecto será invitado por su antiguo alumno y miembro del GATCPAC, Josep Lluís Sert. Recibido en Barcelona como mesías de la sociedad futura, inspirado por su Pla Voisin para París, propondrá la zonificación como solución a gran parte de los problemas urbanos, sociales, políticos o económicos. La metrópoli deberá quedar cuarterada de la siguiente manera: una ciudad nueva y apartada del centro para obreros, dejando la ciudad antigua y su zona de influencia para los negocios (la City), el poder (Centro Cívico) y la habitación de los directivos medios y altos funcionarios: "Clasifiquemos tres clases de población: los que habitan la ciudad [los que tienen el poder, los dirigentes]; los trabajadores cuya vida se desarrolla por mitades en el centro y en las ciudades jardín [los auxiliares, hasta los más modestos, cuya presencia es necesaria a hora fija en el centro de la ciudad, pero cuyo limitado destino tiende simplemente a la organización familiar] y las masas obreras que distribuyen su jornada entre las fábricas de los suburbios y las ciudades jardín. Admitamos, pues, medio millón de habitantes urbanos (en el cinturón del centro) y dos millones y medio en las ciudades jardín.” (Le Corbusier, 1924 [1962], p. 101)

Le Corbusier, considerado por muchos como el promotor de una de las visiones más aristocráticas, elitistas y refinadas de la legitimación social de la tecnocracia y la ingeniería social (Scott, 1998b; Ucelay, 2000), asesorará el Pla Nova Barcelona (rebautizado por él mismo como Pla Macià, en honor al carismático Presidente de la Generalitat del momento). Su carácter controvertido, tendrá su punto fatídico y perverso cuando afirma que no es "de derechas ni de izquierdas" o que "jamás [ha] hecho política” (Perelman, 2018, p. 47). Esta candidez parecería velar el peso más inquietante de sus inclinaciones autoritarias (Scott, 1998a) y su admiración por el poder y el dinero 6 (Perelman, op.cit).

El arquitecto francosuizo precisará aún más la función del urbanismo, con su conocida máxima "Arquitectura o revolución: la revolución puede evitarse". Según sus planes, la arquitectura conseguiría transformar la sociedad y sus ciudades sin necesidad de una revolución económica ni política: "La sociedad está llena de un violento deseo de algo que quizás obtenga o quizás no. Todo radica en eso; todo depende del esfuerzo realizado y de la atención prestada a estos síntomas alarmantes. Arquitectura o revolución. La revolución puede evitarse." (Le Corbusier, 1923, p. 243 [1978])

Así pues, nos encontramos con la misma paradoja que se plantearon los urbanistas decimonónicos como Ildefons Cerdà en Barcelona o el Baron Von Haussman en París: para evitar la revolución de los oprimidos debe desatarse una revolución urbanística. El camino para ello será la cuarterización y cauterización de usos y poblaciones en función de su ocupación laboral y riqueza.

Para Le Corbusier - contrariamente a la opinión de sus anfitriones (Cadenas \& Fernández, 2018)- no cabía redención para la ciudad existente. Defendía una política de tabula rasa para toda la ciudad vieja, dejando solamente en pie los edificios "históricos" o "monumentales" y convirtiendo los solares en jardines (Ares, 2010; Sauquet Llonch, 2014).

Las propuestas urbanísticas que progresaron -siempre y únicamente en los planos- fueron las del GATCPAC. Para Ciutat Vella, aspiraban a una intervención auscultada mediante los estudios previos de mortalidad en las fincas, especialmente de El Raval. Se contemplaba la destrucción de un 30\% del tejido consolidado -que iba a significar el barrido prácticamente absoluto del barrio de Drassanes, estigmatizado ya entonces como el "Barrio Chino" (Fig. 2). Se entiende entonces, las pocas referencias a Le Corbusier en los trabajos previos del GATCPAC y cómo sus diálogos quedan emborronados por discusiones, algunas espurias (ibidem).

\footnotetext{
${ }^{6}$ Sus textos están salpicados de reflexiones dinerarias como la siguiente: "El avión revela este hecho: que los hombres han construido ciudades para los hombres, no para darles placer, para contentarlos, para hacerlos felices, sino para hacer dinero" (Le Corbusier 1935, p. 11)
}

ACE, 15 (4.5) CC BY-ND 3.0 ES | UPC Barcelona, España | Arqueología del futuro en el barrio de El Raval de Barcelona. A propósito de tres inercias del urbanismo tecnocrático y sus efectos indeseables. DOI http://dx.doi.org/10.5821/ace.15.45.10311 


\section{ACE Architecture, City and Environment}

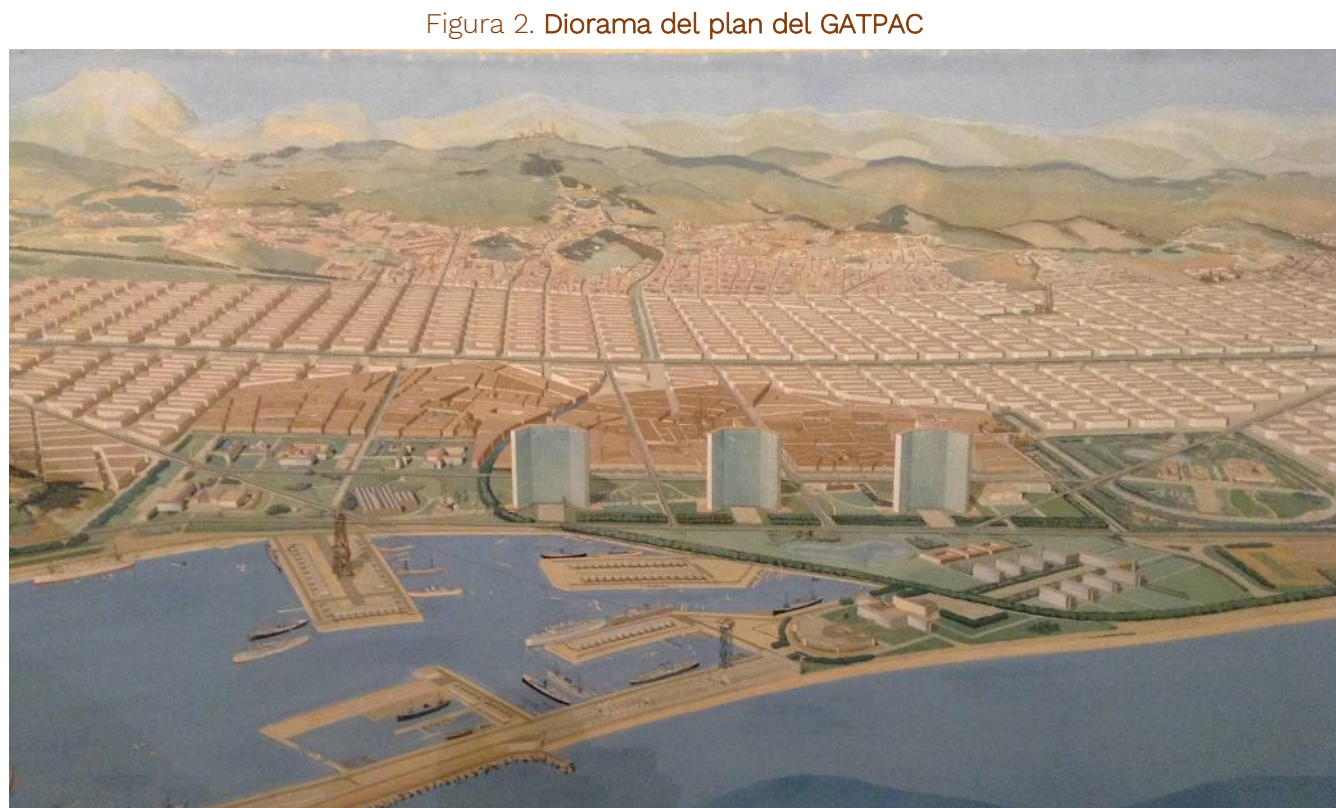

2 Diorama de Josep Torres Clavé donde se ve el "Barrio Chino" convertido en el centro cívico de la ciudad, rodeado de amplias zonas verdes. Fuente: Tarragó, 1972.

Deja también como herencia indiscutible una idea del progreso ambivalentemente alineada con el capitalismo financiero y el aumento del valor del suelo. Fácilmente se vislumbra aquí la tentación autoritaria pero también especuladora. Fue él uno de los primeros descubridores de la ganancia escondida en el diferencial de renta y su original alma salvaje, la gentrificación. Él "modernizó" la idea inmoral e irracional, propia de regímenes racistas o coloniales, de expulsar y diseminar los descapitalizados y destruir sus formas de vida y sus espacios sociales para enriquecerse. Y esto es lo que hemos acordado en llamar progreso y civilización: "Pienso, pues, con toda frialdad, que hay que llegar a la idea de demoler el centro de las grandes ciudades y reconstruirlo, y hay que suprimir el cinturón piojoso de los arrabales, trasladar estos más lejos y, en su lugar construir poco a poco una zona de protección libre que, en su día, dará una libertad perfecta de movimientos y permitirá constituir a bajo precio un capital cuyo valor se duplicará y hasta se centuplicará”. (1924 [1962], p. 59).

Efectivamente Le Corbusier conocía bien las virtudes económicas y políticas de destruir los barrios populares y céntricos y convertirlos en polos de negocios y de residencia para las clases dirigentes (Perelman, 2018). En definitiva, lo que identificamos aquí es cómo, por arte de la tecnocracia, destrucción y especulación pasarían a ser "interés público” y "progreso" económico y social.

Como estamos diciendo, todas estas ideas reformistas no se asumieron acríticamente en el contexto revolucionario que se vivió en Catalunya entre finales de los años veinte y principios de los 30 del siglo XX. Durante estos años, parecería que se estaban invirtiendo ciertas tornas y se vislumbran destellos revolucionarios incluso en las esferas del poder -si el oxímoron lo permite. Así pues, no es atrevido considerar al GATCPAC, primero, como una forma original de tecnocracia progresista para ir deviniendo, conforme se desencadenan los acontecimientos revolucionarios en Catalunya, en una suerte de avanzadilla ilustrada de la revolución proletaria. Ahí están los considerados mejores proyectos del grupo desde una perspectiva redistributiva: La Ciutat de Repos i de Vacances, la Casa Bloc o el Dispensario Antituberculoso.

Pero tan importantes como estos planes y construcciones, serán sus propuestas urbanísticas que hoy podemos considerar revolucionarias. La más importante de ellas fue la que el arquitecto Josep María Sert llamará la Nueva Economía Urbana (1937). Hablaba de "las condiciones únicas e

ACE, 15 (4.5) CC BY-ND 3.0 ES | UPC Barcelona, España | Arqueología del futuro en el barrio de El Raval de Barcelona. A propósito de tres inercias del urbanismo tecnocrático y sus efectos indeseables. DOI: http://dx.doi.org/10.5821/ace.15.45.10311 
insoslayables" de cualquier plan urbanístico: la socialización de la propiedad urbana, la colectivización de la industria de la construcción y la socialización del trabajo profesional de los técnicos. Ésta debió implicar El Decreto de municipalización de la propiedad urbana que será aprobado en junio de 1937. Pero Sert no se quedaba aquí y afirmará: "Mientras los alojamientos constituyan la base de negocios y de especulación para el capital privado, y que su construcción y explotación dependan de empresas que no buscan más que un mayor rendimiento de los capitales invertidos, las viviendas en nuestras ciudades no serán decentes, ya que son la más pura expresión de esta organización financiera. [...] Sólo podremos empezar la regeneración de nuestras ciudades el día en que el alojamiento se considere como un servicio público de primera necesidad y se realice con las técnicas modernas para satisfacer nuestras eternas o nuevas necesidades. Para alcanzar ese resultado es preciso: a) Liberar el suelo de las ciudades. b) Que el alojamiento sea un servicio público.” (Sert en Tarragó, 1972, p. 36)

También cabría señalar como propuesta revolucionaria del GATPAC la "acción complementaria al derribo de edificios malsanos" de El Raval, es decir, "la habilitación inmediata de los numerosos pisos que han quedado desalojados en la ciudad: Diagonal, Paseo de Gracia, Rambla de Cataluña, etc., y parte del Eixample." (GATCPAC, 1937ạ, p. 29)

Esta nueva economía urbana solo verá resuelta la municipalización de la propiedad, aun recibiendo fuertes críticas de sus promotores originales (Cadenas y Fernández, 2018) CNT y POUM (Partido Obrero de Unificación Marxista). La colectivización de la industria de la construcción se llevó a cabo y, de una forma más espontánea que institucional, se habilitaron y ocuparon viviendas abandonadas por los insurgentes. Las medidas más heterodoxas no esperarán a la llegada de los fascistas a Barcelona y serán moderadas o licuadas después de los Hechos de Mayo de 1937. De forma que el "Barrio Chino", para bien o para mal, jamás llegó a sucumbir a los planes de tabula rasa que les tenían reservados los arquitectos modernos. Antes que la piqueta, fueron las bombas de la aviación fascista italiana las que lo destruyeron con la ayuda de la posterior demolición franquista: (...) "el lugar donde la maldad y la porquería tenían su asiento y en el que la gente del hampa y del mal vivir tenían montado sus garitos, prostíbulos, tascas indecorosas, y en cuyo barrio también se confabulaba lo más pernicioso de la sociedad para arremeter contra el orden, la tranquilidad, la paz y el trabajo de Barcelona." (de Otero, 1943, p. 16)

Y como si implícitamente se contemplara que cualquier forma de acabar con este "nidero de inmoralidad" (ibidem) fuera aceptable, así quedó registrado durante décadas en la web del Ajuntament de Barcelona: "El Plan Macià daba soluciones racionalistas e integradas a los problemas del barrio. Pero fueron las bombas de la Guerra Civil las que hicieron los primeros saneamientos urbanísticos al sur de El Raval"8. Esta asociación institucional entre bombardeos y saneamientos urbanísticos es la que nos permite interrogarnos respecto a qué consideración se ha tenido el "Barrio chino" desde las administraciones públicas.

La obsesión por la destrucción del "Barrio Chino" es anterior a su nacimiento como "ludibrio de la capital” (Ibidem). Cerdà ya pensó abrirlo en canal con su propuesta de Gran Vía B y alcanza incluso a quien fuera entonces presidente de la Generalitat Lluís Companys quien, con ocasión de la exposición del Pla Macià en los subterráneos de la Plaza de Catalunya en junio de 1934, le confesó al arquitecto Sert: "Podéis creerme; si pudiera lo demolería a cañonazos" refiriéndose, al "Barrio Chino" (Tarragó, 1972, p. 29).

\footnotetext{
${ }^{7}$ Se conocen como Els Fets de Maig el enfrentamiento entre libertarios de CNT y POUM contra las tropas gubernativas de los comunistas y de Esquerra Republicana, apoyados por el Gobierno de Azaña, presionado a su vez, por la URSS de Stalin.

${ }^{8}$ Así se contemplaba en la web oficial del Ajuntament de Barcelona, en su apartado sobre la historia de El Raval. Después de quejas de vecinos de El Raval, esta fórmula fue sustituida por otra más moderada: "El Plan Macià daba soluciones racionalistas e integradas a los problemas del barrio. Pero primero la Guerra Civil Española y después la larga dictadura franquista condenaron El Raval a una degradación urbana y social aún mayor." Ver https://ajuntament.barcelona.cat/ciutatvella/es/el-distrito-y-sus-barrios/el-distrito-y-sus-barrios/el-raval/historia-delraval.
}

ACE, 15 (4.5) CC BY-ND 3.0 ES | UPC Barcelona, España | Arqueología del futuro en el barrio de El Raval de Barcelona. A propósito de tres inercias del urbanismo tecnocrático y sus efectos indeseables. DOI http://dx.doi.org/10.5821/ace.15.45.10311 
Expuesto esto, nos podemos arriesgar aquí a proponer una nueva investigación para contrastar la hipótesis, según la cual, tanto el Ayuntamiento postfranquista como el President Companys, podían estar reproduciendo una suerte de inconsciente colectivo impregnado de una racionalidad instrumental y clasista respecto a cómo liquidar las zonas más conflictivas de la ciudad. Cabe recordar cómo Le Corbusier dejará escrito que la única manera de acabar con los bajos fondos será el hacer la tabula rasa: "El avión inculca, sobre todo, una nueva conciencia, la conciencia moderna. Las ciudades, con su miseria, deben ser demolidas. Deben ser destruidas en gran medida y construirse nuevas ciudades. [...] Las ciudades deben salir de su miseria, pase lo que pase. Hay que destruir barrios enteros y construir nuevas ciudades." (Le Corbusier, 1935, pp. 15, 87) .

"El aeroplano acusa a la ciudad". Así se entiende más precisamente que el espíritu urbanístico de la época entendía que los defectos de estos barrios "eran tantos que no podían rectificarse por separado lo cual exigía esfuerzos y recursos desmedidos [...] se podían arrasar las ciudades heredadas y evacuar los lugares que ocupaban para construir urbes nuevas, planificadas hasta el último detalle" (Bauman, 2001, p. 57). Esta regeneración de raíz se entendía como la única respuesta posible a décadas de intereses arbitrarios, y daba por hecho que sus intereses eran ecuménicos y no influenciados por el lucro, el poder o el deseo de distinción.

Para Le Corbusier, se trataba entonces de responder a la decadencia, el desorden, la indisciplina, la criminalidad, la suciedad y el caos que debían ser extirpados tal que un cáncer ${ }^{10}$ que estuviera acabando con la ciudad. "Reclamamos, en nombre del barco de vapor, el avión y el automóvil, el derecho a la salud, la lógica, la audacia, la armonía, la perfección.” (Le Corbusier 1934, p. 134). Recordando que contemplaba los abigarrados centros urbanos, como el de París o el de Barcelona, como un "puercoespín" o el mismísimo "infierno de Dante", proclamó que "[la] ciudad sería una entidad organizada, serena, contundente, aireada, ordenada” (Le Corbusier 1934, p. 134). Será también el mismo Le Corbusier quien considerará la ciudad de Saint-Dié, "bombardeada sistemáticamente durante tres días" - una vez designado como responsable de su reconstrucción en 1945- "un espléndido problema" (Le Corbusier citado en Lahuerta, 2012, p. 35).

Lo que contempla esta hipótesis es el hecho probado que la destrucción del "Barrio Chino" de Barcelona, así como su análogo Marsellés, Le Vieux Port, se arrasaron con medios militares primero, para luego ser barridos con la piqueta urbanística. El primero mediante las bombas fascistas y el segundo mediante la detonación de todo el barrio ejecutada por los nazis ${ }^{11}$. No se puede olvidar que estos "bajos fondos" europeos fueron situados en la mirilla de los francotiradores del progreso y la modernidad, es decir, para nada desde principios reaccionarios. Al contrario, fue el enorme prestigio del eugenismo social de esta época y su influencia sobre el pensamiento liberal y racionalista, los que hicieron concebibles e incluso respetables, estas enormes eugenesias urbanas ${ }^{12}$.

\footnotetext{
${ }^{9}$ La procedencia de estas citas es de uno de sus textos menos conocidos, Aircraft. Aquí Le Corbusier venerará, a veces de manera velada, a veces, inquietantemente explícita, la capacidad destructiva de los bombarderos y sus posibles efectos benefactores en la construcción de la Civilización Maquinal (Le Corbusier, 1935).

10 Incluso des del GATCPAC se utilizaba la metáfora del cáncer para referirse a barrios como Drassanes cuando afirmaba "Por imperativo de la profilaxis más elemental, debemos evidenciar hoy el carácter del cáncer barcelonés del llamado 'barrio chino' como caso clínico “típico” existente en casi todas las grandes urbes” (GATCPAC, 1932, p. 31).

${ }^{11}$ Esta hipótesis debería interesarse por la conocida como Opération Sultan. Llevada a cabo en el barrio portuario de Marsella en 1943 por la Gestapo y la policía colaboracionista del régimen de Vichy. Se trata de la detonación de la zona habitacional del Vieux Port y la demolición de dos barrios más contiguos a éste. La Gestapo deportó a 20000 personas (Guicheteau, 1973). Recientemente, dos de sus supervivientes, han interpuesto una demanda contra el Estado Francés por crímenes contra la humanidad. Ver Marseille, 1943 :autopsie d'un crime contre les quartiers populaires | Panoramiques Mediapart. Consultado en diciembre de 2020 y Guicheteau, 1972

${ }_{12}$ Cabe recordar que la eugenesia como instrumento científico para mejorar "la raza" fue aplicada por el régimen nazi en sus campos de exterminio. El problema es que, desde principios de siglo XX, le eugenesia gozaba de un enorme reconocimiento en prácticamente todas las esferas políticas y se consideraba una medida progresista, por científica. Una voz tan autorizada como la del presidente de la American Psychiatric Association declaraba en 1914: "Una curación radical de los males que se derivan de la asistencia a una clase de deficientes sin recursos se llevaría a cabo si todos los débiles de espíritu, los alienados incurables, los epilépticos, los imbéciles, los criminales contumaces, aquellos que sufren manifiestamente una carencia de la voluntad y todos los borrachos inveterados fuesen esterilizados, esta proposición
}

ACE, 15 (4.5) CC BY-ND 3.0 ES | UPC Barcelona, España | Arqueología del futuro en el barrio de El Raval de Barcelona. A propósito de tres inercias del urbanismo tecnocrático y sus efectos indeseables. DOI http://dx.doi.org/10.5821/ace.15.45.10311 
Así pues, la solución pasaría por la racionalidad y la eficiencia del urbanismo que, tanto puede destruir mediante la piqueta ${ }^{13}$ como aprovecharse de los efectos de un bombardeo aéreo o incluso como comenta Le Corbusier en su Aircraft, considerar que "la única manera de sanear los barrios chinos, los bajos fondos, serán bombardeándolos" (Granell Trias, 1997, p. 119). Curiosamente, "es bombardeado, sobre todo, el lugar donde se tenían que levantar los rascacielos cartesianos" (ibídem) ${ }^{14}$. Pareciese como si el barrio portuario fuese un territorio, todo él, habitado exclusivamente por variantes de Homo Sacer"15. Todo dirigido hacia una suerte de aterradora "solución final" de todos los problemas sociales (Bauman, 2001; Scott, 1998a). Llegados a este punto, no se nos es permitido mirar hacia otro lado. Si el objetivo de tabula rasa está emparentado con una "la solución final" nutrida por la arendtiana banalidad del mal (Arendt, 1967), es un interrogante que amerita una nueva investigación. Como oportunamente interpreta Lahuerta, se cubrió con el velo de la genialidad, la voluntad destructora y la afinidad inquietantemente moderna entre la destrucción y la purificación: "Aunque le costó el recelo o la amistad de algunos de sus colaboradores más fieles, como Pierre Jeanneret o Charlotte Perriand, ¿cómo no iba a poder justificar el reformador apolítico los medios con los fines, más allá, en efecto, del bien y del mal? No será necesario hablar aquí de la "banalidad del mal": se sobrentiende. (2012, p. 34).

Podríamos añadir que, más allá de una banalidad del mal, lo que estamos descubriendo aquí es una "racionalidad del mal". Será el autor de Modernidad y Holocausto, quien hará notar que toda violencia tiene una intención que, en este caso, puede ser regenerar, recuperar o incluso, emancipar. Para ello, recupera una cita de Albert Camús, donde hace notar el hecho innovador que, "por primera vez en la historia, actos atroces se cometen bajo la bandera de las más bellas consignas” (Bauman \& Tabet, 2017, p. 294)

\subsection{El Modelo Barcelona o la legitimación democrática de la destrucción de El Raval}

La huella tanto de los planes como del conjunto de acciones llevadas a cabo por estos jóvenes arquitectos se había ignorado demasiado tiempo (Bohigas, 1960). Esta es la opinión de una de las figuras más relevantes de lo que será la "Reconstrucción de Barcelona" después de la muerte del dictador. Según Oriol Bohigas (responsable de la última gran intervención en El Raval -la Illa Robadorademás de arquitecto responsable e insignia de la transformación de la Barcelona posfranquista), "[M]ientras estas situaciones [falta de eficacia urbanística, modernización de la arquitectura, compromiso social y económico] perduren casi en todo el mundo, las nuevas generaciones deben ser todavía fieles a los programas iniciales." (1960, p. 44). Este texto lo tituló pertinentemente "Homenaje al GATCPAC" y significará una primera alabanza del grupo. Décadas más tarde, aún destacará la importancia de estos profesionales, incluso, por encima de los gobernantes. Ellos fueron, a criterio de Bohigas, los artífices de una nueva arquitectura y, por extensión, de un nuevo urbanismo en Catalunya. Para quien fuera Delegat de l'àrea d'urbanisme de l'Ajuntament de Barcelona entre 1977

resulta evidente por sí misma. Por estos medios podríamos acabar casi totalmente, si no absolutamente, en uno o dos decenios, con la reproducción de los deficientes psíquicos con tanta seguridad como podríamos erradicar la viruela si cada persona en el mundo pudiese ser vacunada con éxito" (citado por Castel, 1983, p. 226). Una de las figuras más relevantes en el campo de la eugenesia fue Julian Huxley (hermano del autor de Brave New World, publicado elocuentemente en 1932), vicepresidente de la Sociedad de la Eugenesia Británica desde 1937 y posteriormente nombrado presidente hasta 1962. Preocupado por la educación de la infancia fue promotor de la UNESCO y su primer director general en 1946.

${ }^{13}$ Incluso en etnografías relativamente recientes, se constata la popularización de la idea que, según la cual, para acabar con los "problemas sociales" se deben demoler calles o barrios. En este caso, un nuevo vecino de la zona nueva d'en Robador, expresaba lo siguiente "Yo pienso que la única solución -aunque habrá gente que discrepe de lo que opino- es tirar abajo los pisos que están medio destruidos y construir nuevos. Y entonces sí vendrá mucha más gente, pero es que nosotros no sobrepasamos todavía el porcentaje, somos muy pocos” (Fernández, 2014, p. 208)

${ }^{14}$ Ver Figura 1

${ }^{15}$ Figura del Derecho Romano clásico que castiga a un hombre a que, cualquier otro hombre, pueda arrebatarle la vida impunemente (Agamben, 2010).

ACE, 15 (4.5) CC BY-ND 3.0 ES | UPC Barcelona, España | Arqueología del futuro en el barrio de El Raval de 10 Barcelona. A propósito de tres inercias del urbanismo tecnocrático y sus efectos indeseables. DOI http://dx.doi.org/10.5821/ace.15.45.10311 
y 1984 y posteriormente arquitecte en cap, no se puede comprender la importancia de este nuevo urbanismo y su imbricación con los anhelos sociales y políticos de la sociedad, si no se tiene presente que fueron estos arquitectos juntamente con toda una escuadra de profesionales -y no los políticos electos ni mucho menos la gente común- los que empujarán a las Consellerias republicanas a poner las medidas oportunas para lograr una sociedad más progresista, abriendo las puertas de una modernidad "tan exigente que apenas se desarrollaba sólo en ámbitos internacionales aún restringidos." (2010, p. 10).

Como es sabido, los planes para "sanear" El Raval del GATCPAC no pudieron ser implementados hasta la muerte del dictador Franco ${ }^{16}$ y, más elocuentemente, hasta dos años después de que Barcelona fuera escogida sede de los Juegos Olímpicos en 1992. La rehabilitación de El Raval se encontró con la buena -o mala fortuna, según se mire- de coincidir en el tiempo con el gran acontecimiento que cambiará para siempre y en un periodo de tiempo muy corto, la faz de El Raval. Desde el momento en que Barcelona se elige sede de los JJOO, en 1986, arranca una campaña mediático-política que urgirá a las autoridades a intervenir drásticamente el barrio. A partir de una más que controvertida "batalla entre traficantes" en la conocida como "Isla Negra" (o manzana Sant Ramon), dos manzanas de fincas, es decir, 26 edificios con sus correspondientes 560 viviendas y 70 locales comerciales, fueron íntegramente destruidas (Rufián Roto, 2011). Será esta intervención la que dará lugar a la constitución de la empresa de capital mixto PROCIVESA que será la encargada de toda la remodelación del distrito de Ciutat Vella.

En 1988 se pensó que "en ese momento [...] no había nada que justificara su rehabilitación", tal y como reconocía el entonces máximo responsable de PROCIVESA, Martí Abella, en un programa de la televisión pública catalana (Colom, 2005). Él mismo añadía después su pesar al comprobar que, contrariamente al sentido común propio de los tecnócratas del momento, "en el barrio chino vivía mucha gente muy normal” (Colom, op.cit). Quizás nadie, ni antes ni después de él, expresó más desacomplejada y honestamente las ruinas humanas que dejan las demoliciones de viviendas en zonas densamente pobladas. Tanto Martí Abella como su colaboradora Carme Gual, nos reconocían en una entrevista que hoy no se hubiesen hecho intervenciones tan contundentes como la obertura de la Rambla de El Raval pero que, en aquel momento, "no había nada que valiera la pena recuperar" y que, por otro lado, si no se hubiera intervenido en su momento, "ahora estaríamos como en las favelas de Brasil, con los militares en la puerta” (Entrevista Carme Gual, octubre 2011). Los antiguos vecinos y trabajadoras de la enorme zona afectada no dejaron rastro y se esfumaron del "Barrio Chino" para no volver. Poco después, el PERI (Plan Especial de Reforma Interior) -solo en la "zona sur"- dejará un saldo de nueve manzanas arrasadas más que significarán un total aproximado de 2500 viviendas y 450 locales comerciales derribados (Fernández, 2014). Como en el cuadro de Klee, en el caso de El Raval, este progreso ha dejado un rastro de destrucción de tejido urbano y muerte de barrios enteros difíciles de obviar.

El relato asumido por Oriol Bohigas y demás responsables "culturales” de esta Barcelona en reconstrucción será el del GATCPAC, pero las ejecuciones se parecerán más a las amplias propuestas de destrucción imaginadas por Le Corbusier. Recordemos que el GATCPAC prefiere una intervención "de cirujano antes que de arquitecto". Para Bohigas, además, deberán ser homeopáticas o de acupuntura (1986). Pero esto no fue así para gran parte de El Raval17.

\footnotetext{
${ }^{16}$ El barrido de escombros que supuso la construcción de la Av. Garcia Morato (actual Drassanes), respondía más a la propuesta de "obertura" de la Gran Vía B de Cerdà. Aun así, como estamos viendo, de nuevo ni en periodos republicanos, ni dictatoriales, ni recuperada la democracia, nadie pone en duda la urgencia en no dejar rastro del malogrado "Barrio Chino".

17 Según Enric Mir, Profesor del Departamento de Proyectos de la Escola Técnica Superior d'Arquitectura de Barcelona, "La actuación que está llevando a cabo el ayuntamiento pasa por la apertura de estos grandes agujeros que están provocando una operación traumática, en términos médicos es como si en un campo de batalla, un soldado herido de un pie vuelve al hospital de campaña y el cirujano le corta la pierna. El problema pues es que el soldado ha perdido una pierna cuando, seguramente, con otros medios el soldado se hubiera salvado". Extracto de una entrevista aparecida en el documental Perill al Centre Històric de Barcelona (Mallarach, 1999).
}

ACE, 15 (4.5) CC BY-ND 3.0 ES | UPC Barcelona, España | Arqueología del futuro en el barrio de El Raval de Barcelona. A propósito de tres inercias del urbanismo tecnocrático y sus efectos indeseables. DOI http://dx.doi.org/10.5821/ace.15.45.10311 


\section{ACE Architecture, City and Environment}

Tal y como se nos recordaba, "fueron las bombas de la Guerra Civil las que hicieron los primeros saneamientos urbanísticos al sur de El Raval”. Éstas destruyeron más de 1500 viviendas ${ }^{18}$, una cifra inferior a los 2500 hogares desaparecidos que implicaron las intervenciones una vez restaurada la democracia. Y esto nos lleva a proponer una nueva hipótesis ad-hoc. Si tenemos presente que la gran destrucción del barrio de Drassanes propuesta por el GATCPAC ya la habían llevado a cabo las bombas, ¿podemos entonces considerar las operaciones urbanísticas de la Rambla de El Raval, Illa Robador y Sant Ramon como intervenciones auscultadas, de cirujano homeopáticas? O es que, cuando les tocó el turno a los responsables últimos del "Modelo Barcelona", ¿el barrio ya había mutado y traspasado la mítica frontera de Nou de la Rambla para instalarse en la Illa Robador y, por tanto, desplazado también el objeto sobre el que se debía hacer tabula rasa? (Figura 3)

Figura 3 Calle d'En Robador una tarde del verano de 2012

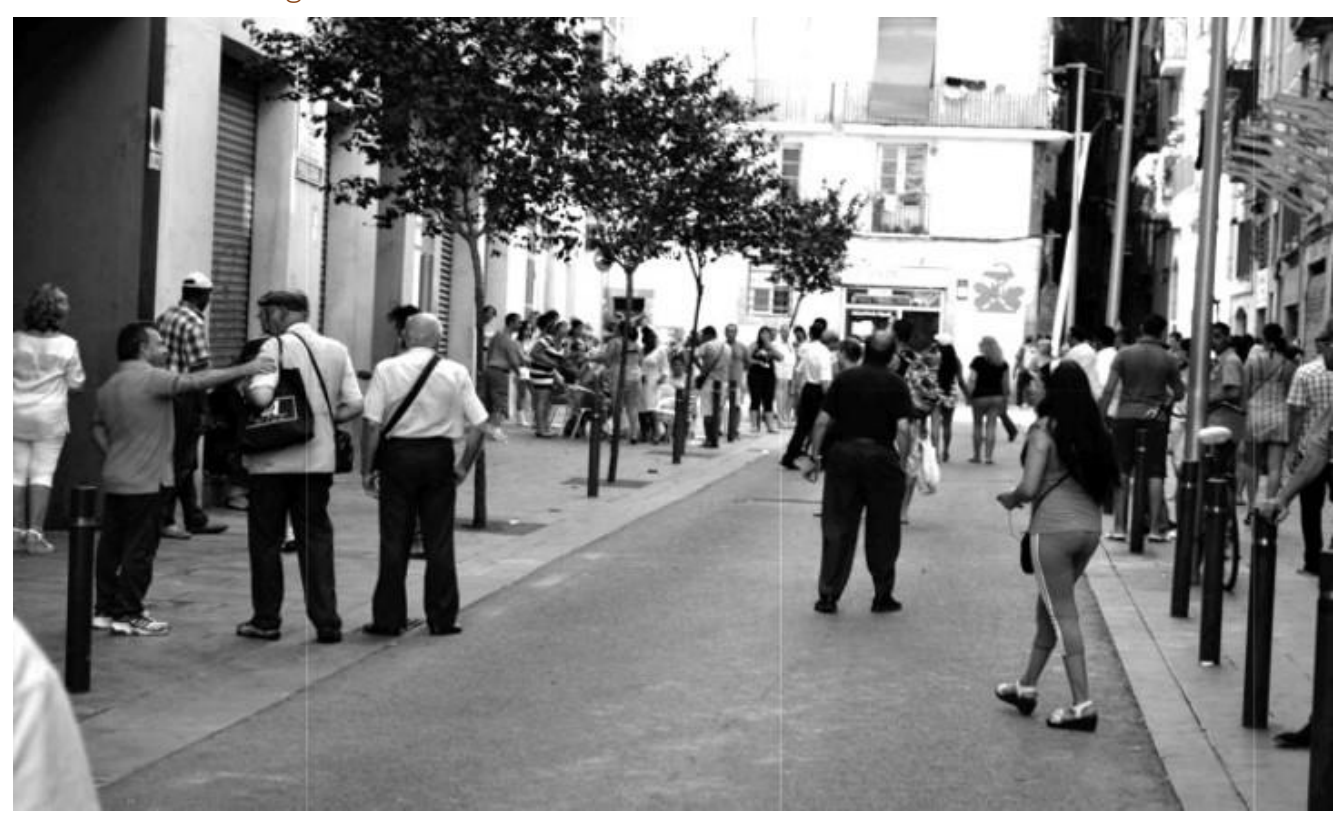

Fuente: Sirvent Ivorra y Carreras Gutiérrez, 2012

Nuevamente, en la etapa democrática, las mediaciones urbanísticas también se justificarán como capaces de resolver los "problemas sociales" del barrio, hasta el punto de que una actuación como la llevada a cabo en la Illa Robador, "relega a un segundo plano el trabajo social, priorizando la estructura urbana y la mejora del espacio público" (Bohigas, Ferrer y Sust, 2002) y, por tanto, la tradicional estrategia preventiva que había sido la redistribución de la riqueza (López y Alabart, 2011). Sus efectos - deseados o no- en El Raval parecerían ser que, mediante las intervenciones urbanísticas, se declaran acrónicos los conflictos de clase y que, por derivación, la política se retrotraiga a una única función: adecuarse a las necesidades de la técnica y, a poder ser, de la más avanzada de ellas, la urbanístico- arquitectónica.

A continuación, nos detendremos a reflexionar sobre la persistencia del urbanismo tecnocrático hoy día, en concreto, en la planificación de las ciudades ideales contemporáneas etiquetadas como Smart Cities.

\footnotetext{
${ }^{18}$ En total se calcula que estos bombardeos causaron más de 2500 muertos y una cifra cercana a los 3200 heridos. Véanse Villarrolla (1991) y Albertí y Albertí (2004, pp. 40-43).En otro enclave obrero de Barcelona, el barrio de Sant Pere y Santa Caterina, también se produjeron bombardeos contra población civil. Lo que une a estos dos barrios céntricos y desasosegados es que ambos mantuvieron los escombros de las bombas durante décadas. En el caso de Drassanes, hasta la urbanización de la Avenida Garcia Morato (actual Drassanes) en 1968 y en el caso de Sant Pere, hasta finales del siglo XX.
}

ACE, 15 (4.5) CC BY-ND 3.0 ES | UPC Barcelona, España | Arqueología del futuro en el barrio de El Raval de 12 Barcelona. A propósito de tres inercias del urbanismo tecnocrático y sus efectos indeseables. DOI: http://dx.doi.org/10.5821/ace.15.45.10311 


\section{La Smart City, remudado epítome de la tecnocracia}

Como hemos visto, algo que resulta interesante y evocador sobre la reconstrucción postfranquista de la ciudad es descubrir los usos retóricos, proyectuales y prácticos que se derivan de esta relación de selección, afirmación, reconocimiento o negación interesada de fragmentos escogidos de planes anteriores. En el caso del Pla Macià, se ha copiado el discurso proyectual y sus efectos esperados, pero se han obviado las cuestiones más peliagudas como la municipalización del suelo o la ocupación libre de las viviendas abandonadas por los sublevados.

Entonces, ¿qué nos queda de todo esto en la actualidad? Pues la insistencia ahora ya, sin excusas, del enfoque científico racional en el diseño de las ciudades y concretamente en su versión contemporánea, las Smart Cities. La Smart City se puede considerar como ideología urbanística que lleva al paroxismo la fe absoluta en la tecnología para mejorar, en todo el amplio sentido de la expresión, la eficiencia de las ciudades capitalistas. Así pues, y como ya hemos visto, las "large scale master-planned cities”, apoteosis del Movimiento Moderno y típica exigencia de Le Corbusier para sus ciudades, se basaron explícitamente en la creencia de que los problemas de la ciudad podían solucionarse gracias a una aproximación científica del diseño urbano.

Ahora, las Smart Cities -según IBM, una de las grandes compañías involucradas en su desarrollo- se basan en la creación constante de "new data that can be used to 'monitor, measure and manage' urban life by 'leveraging information to make better decisions... anticipating and resolving problems proactively... [and] coordinating resources to operate more efficiently." (Shelton et al, 2015). Esta tendencia a simplificar el funcionamiento urbano se basa, nuevamente, en el implícito de la aparente neutralidad de los datos. Para conseguir la fantasía del "management of life -human and machine" eficiente la ciudad se reduce a una serie de variables y a unos determinados patrones de comportamiento donde la imprevisibilidad de lo urbano parece molestar: "el ciudadano, como ser voluble, imprevisible y desconcertante, representa la molestia que hay que parametrizar, hasta el punto de que su comportamiento pueda ser sustituido por algoritmos que intenten preverlo" (Halpern, Lecavalier, Calvillo, y Pietsch, 2013, p. 278). De igual forma, los elementos idiosincráticos de la vida urbana, como son el conflicto o las visiones contradictorias respecto del significado de orden y desorden, se proponen aplacar gracias a "un control en tiempo real [...] que posibilitará someter por fin esta complejidad a una cuestión de decisiones automáticas basadas en datos supuestamente neutrales" (Fernández, 2014, p. 130).

Como ya sabemos, "the data are socially constructed" y tradicionalmente se han movilizado "as a kind of depoliticising device, collected and legitimised for use in urban politics and policymaking." (Shelton et al., 2015, p. 22). En este sentido, la traducción de la ciudad a un lenguaje común, "el lenguaje de IBM" (Söderström, Paasche, y Klauser, 2014) donde las grandes compañías de alta tecnología pueden actuar, tiene claras consecuencias políticas: [...] "La metáfora orgánica o sistémica también crea una entidad ficticia 'la ciudad' que apoya 'una búsqueda de políticas de consenso, en la que los reclamos de la minoría o de los grupos impotentes, marginados o no convencionales se consideran factores perturbadores en la búsqueda de políticas que beneficien "al conjunto social"". (Söderström et al., 2014, p. 314)

De nuevo, el régimen discursivo de estos "modelos urbanos perfectos" se provee de la "legitimidad de la ciencia" y aspira a la "neutralidad política". De esta manera, "smart technologies can optimize any system, from the surveillance of political opponents to waste management. It can be sold to democratic regimes such as Denmark as well as to much less democratic ones such as Syria" o China (Söderström et al., 2014, p. 318). Lo que nos recuerda a la fría ambivalencia lecobursiana $-y$ sin tapujos- respecto a prestar sus servicios a regímenes totalitarios o democráticos, estalinistas o fascistas (Perelman, 2018). "Al igual que Le Corbusier vio el urbanismo funcionalista como un modelo apolítico que estaba dispuesto a proponer a la India poscolonial, la Roma fascista o la Rusia estalinista,

ACE, 15 (4.5) CC BY-ND 3.0 ES | UPC Barcelona, España | Arqueología del futuro en el barrio de El Raval de Barcelona. A propósito de tres inercias del urbanismo tecnocrático y sus efectos indeseables. DOI: http://dx.doi.org/10.5821/ace.15.45.10311 
las tecnologías urbanas inteligentes son un ómnibus listo para detenerse dondequiera que se encuentren clientes" (Söderström et al., 2014, p. 318).

Así pues, el relato de las Smart Cities contribuye a introducir un nuevo imperativo moral donde la "inteligencia" se convierte, como la creatividad, en un activo necesario para las ciudades. Ahora, todos los agentes "[...] están organizando sus conocimientos, experiencia y servicios para poder venderlos a otras ciudades. [...]. Es esta exportabilidad lo que importa en el banco de pruebas.". (Halpern et al., 2013, p. 297).

Podemos añadir que esta visión propia de un nuevo y remozado tipo de autoritarismo tecnocrático de estética progresista (Scott, 1998b), sólo parece haber sido "superada" en la última -aunque poco o nada desplegada- de las etapas del urbanismo barcelonés ${ }^{19}$.

\section{Consecuencias de la ilusión tecnocrática en el urbanismo. Tres inercias innegociables de la planificación contemporánea}

Una de las consecuencias que emerge de esta fe en la tecnocracia es la preeminencia de los medios creados sobre los fines deseados. Desde este presupuesto, sostenemos que las intervenciones urbanísticas analizadas -entre 1988 y 2012- en El Raval, habrían comportado, primero: una naturalización del moderno odio al otro, basado en este caso no en retóricas racistas sino en otras de carácter fundamentalista cultural (Stolcke, 1995), constriñendo de manera discrecional los comportamientos en el espacio público, concediendo privilegios a los nuevos vecinos y acosando a antiguos vecinos, trabajadoras y "inmigrantes" en El Raval. Segundo: una inversión del bien y, por tanto, una alteración de la concepción de las prácticas agresivas institucionales -como los urbanismos citados- o represivas sobre el Espacio Público -como el civismo-, hasta que se convierten en "fuerza necesaria" 20 para mejorar y salvar el barrio de la degradación o de que se convierta en el "Harlem barcelonés"(Puigvert, 2005) y; tercero: la expulsión de miles de vecinos propulsando la "normal rotación de residentes [y por tanto] una lógica renovación de persones" (Abella, 2004, p. 94) o la ya, de manera menos eufemística anunciada, "limpieza étnica de los señoritos" contra los bajos fondos de Barcelona (Vázquez-Montalbán, 1993b). A continuación, ofrecemos una explicación de estos tres efectos no esperados -o no deseados- de un urbanismo considerado progresista.

\subsection{La normalización produce anormales}

La ciudad utópica es concebida exenta de pasado y con un futuro que es simplemente una proyección fijada en un tiempo previsible e inalterable. Como acabamos de ver, la ciudad ideal moderna se planificó, tal y como interpretó Foucault (1976), dividiéndola en barrios de dirigentes que disciplinan y barrios de obreros que hay que disciplinar. Así pues, la ciudad se proyecta de manera desacomplejada como un espacio de fiscalización donde se articulan "mecanismos disciplinarios de control sobre el cuerpo, sobre los cuerpos, gracias a su reticulación, mediante su subdivisión, mediante la distribución de familias (cada una en una casa) y de los individuos (cada uno en una habitación)". En otras palabras,

\footnotetext{
19 Con la llegada del gobierno de "los Comunes" (una agrupación de partidos progresistas socialdemócratas) en 2015, después de cuatro años de gobierno conservador en el consistorio barcelonés, el concepto Smart City devino prácticamente tabú en la retórica urbanística oficial. Con el arquitecto Josep María Montaner como primer Regidor d'Habitatge i Rehabilitació, se inclinó el discurso y las prácticas hacia un urbanismo "sostenible", "verde" o "táctico". Aun así, consideramos que, efectivamente, este es un "urbanismo del mientras tanto" que podría ponerse en crisis cuando los agentes inmobiliarios y financieros globales recuperen su impulso característico (Cadenas Álvarez, 2018). Por otro lado, entre las nuevas promociones de arquitectos, se proponen intervenciones alejadas de criterios tecnocráticos y más centrados en el co-creación artística y los diseños participativos (Sève y Redondo, 2020)

${ }^{20}$ Cabe destacar la muerte del vecino de El Raval Juan Andrés Benítez en una simple reducción por parte de ocho policías en octubre de 2013 en la Calle Aurora del mismo barrio.
}

ACE, 15 (4.5) CC BY-ND 3.0 ES | UPC Barcelona, España | Arqueología del futuro en el barrio de El Raval de Barcelona. A propósito de tres inercias del urbanismo tecnocrático y sus efectos indeseables. DOI: http://dx.doi.org/10.5821/ace.15.45.10311 
se establece "una especie de control policial espontáneo ejercido mediante la disposición espacial" (Foucault, 1976, pp. 202-203).

Justamente, el primer conjunto de inercias detectadas en la ideación y práctica urbanística tiene que ver con la producción de una clase social que no acata las lógicas disciplinarias descritas por Michel Foucault. Se trata de una clase que originalmente fue etiquetada como laboriosa, después como peligrosa y actualmente como prescindible o, en su versión más contundente, como indeseable. Y esto es exactamente lo que ha pasado en El Raval. Fue uno de los primeros barrios industrializados del sur de Europa; como es sabido, se convirtió en el corazón de la vida combativa, escenario de multitud de confrontaciones entre obreros y la patronal (Ealham, 2005) y, por último, en la etapa que se inicia al abrigo del presente siglo, en espacio de expulsión de población descapitalizada y desembarque de clases creativas concentradas en el consumo conspicuo de la ciudad (Fernández, 2014). Estos cambios se interpretan aquí a la luz de la genealogía del racismo, es decir, de la emergencia del biopoder. En nuestras sociedades contemporáneas, el descrédito del racismo como retórica de segregación habría dado paso al "fundamentalismo cultural" (Stolcke, 1995).

Es desde este concepto que se hace comprensible el hecho que nuevos vecinos de la calle d'En Robador de El Raval rechacen la interacción con los vecinos tradicionales ya que "esta gente no sabe... [...] el gran problema [es] que el nivel cultural de la gente que vive aquí es muy bajo" (Vecino de Robador citado en Fernández, 2014, p. 207).

En las sociedades donde ha aparecido el biopoder como nueva forma de gobierno que complementa y perfecciona las tecnologías disciplinarias (Foucault, 1978), es primordial el cuidado de la sociedad entendida como cuerpo social. Como es sabido, la relación conocimiento-poder aquí viene dada por la biología y la medicina y, más precisamente, por su homologación a través de las ciencias sociales y humanas, la geografía y la demografía. La traducción torpe de los conceptos darwinianos permitirá una retórica justificativa hacia un nuevo proceso de jerarquización. Las estadísticas establecerán como medidas centrales la norma y la moda. Indicarán los comportamientos beneficiosos para la salud del cuerpo social y aquellos que huyan de la fila se les señalará como anormales, insanos o desviados.

El cuidado de la especie identificará amenazas como son la insalubridad, la suciedad, las enfermedades infecciosas, las deformidades o los comportamientos desordenados con el objetivo de preservar la raza. Discurso y prácticas que, indefectible y obviamente, generará el racismo: es decir, considerar la propia raza como la sana, la fuerte, la superior y, por tanto, la que se debe preservar frente a los otros (Foucault, 1976).

En nuestro caso, desde sus orígenes, poderes oficiales y oficiosos sobre El Raval promovieron que los hijos del "Barrio Chino" no eran propiamente humanos: "[U]na humanidad moralmente tarada [...] Los niños nacían ya predestinados. Su carne estaba marcada y su espíritu también. El ambiente iría madurando a la una y el otro, hasta convertirles en piltrafas humanas, en auténticos ex hombres ¡Cuánta ignominia, ¡cuánta humanidad vergonzante y vergonzosa, cuánta lacra vital tuvieron su natural asiento en aquel dédalo de callejuelas!” (Paquer, 1962, pp. 6-7)

La novedad de esta tecnología es que funciona en la medida en que los enemigos que se deben eliminar no son los adversarios políticos sino los peligros, externos e internos, en relación con la población. La victoria debe ser la eliminación del peligro biológico que representan los desviados, los anormales, los otros amenazantes por su simple presencia. Así se categorizarán los segmentos irredentos de la población como disolutos, corruptos y peligrosos.

Este discurso y prácticas se pueden observar en todo el proceso de demonización de El Raval (Mcdonogh, 1987). En el marco de lo que Stanley Cohen llamaría Moral Panics (2002), desde los años

ACE, 15 (4.5) CC BY-ND 3.0 ES | UPC Barcelona, España | Arqueología del futuro en el barrio de El Raval de 
veinte del siglo pasado hasta hoy en día, cronistas y políticos de todas épocas y tendencias han acusado al "Barrio Chino" y, a menudo, por extensión al Raval de ser: "la úlcera de la ciudad [...] el refugio de la gente mala" y un "inframundo", "una zona prohibida mucho peor que cualquier cosa en Marsella, Génova o Londres" (Madrid, 1925); un lugar "donde la maldad y la porquería tenían su asiento" (de Otero, 1943); un "degradado parapeto del hampa" (Paquer, 1962, p. 9); ya en 2005 se podía haber convertido en "un inmenso barrio sin ley. El Harlem del sur de Europa. Una selva marginal, infranqueable en el corazón de Barcelona" (Puigverd, 2005); en 2009 un "lugar maldito" donde ha sido imposible afrontar "la prostitución, las drogas, la delincuencia, la inmigración, la especulación, el turismo masivo de bajo coste y las normas de civismo" (Benvenuty, 2009) y, finalmente, en 2017 un barrio donde "hasta que no corra sangre, no harán nada" (Pérez, 2017). Es esta una de las maneras con las que se puede justificar el asedio y la expulsión de poblaciones enteras en marcos formalmente democráticos y liberales. La biopolítica posibilita así la naturalización del argumento, según el cual, para que el barrio sea saneado hay que "matar" -física o políticamente- estos elementos "insanos" que contaminan el resto de los segmentos sociales del barrio y de la ciudad.

\subsection{Las "soluciones" urbanísticas producen "problemas sociales"}

Otro de los efectos no previstos de esta fe en la tecnocracia será la producción de problemas sociales. Para el sociólogo Zygmunt Bauman, cuantas más tecnologías inventemos para "solucionar los problemas sociales", más cuestiones se vuelven desasosegantes, molestas e inadecuadas sobre las cuales se debe intervenir. Y es que "la tecnología hoy se desarrolla porque se desarrolla. Hoy no sirve para solucionar problemas, la disponibilidad de determinada tecnología redefine las diferentes partes de la realidad humana como problemas que claman ser resueltos". Esto sólo puede darse en una cultura burocrática "que nos incita a considerar la sociedad como un objeto a administrar, como una colección de 'problemas' varios a resolver", como un legítimo objeto de la "ingeniería social” y, en general, como "un jardín que hay que diseñar y conservar a la fuerza en la forma en que fue diseñado" separando las malas hierbas de las plantas cultivadas (2001, pág. 251-253).

Tal y como hemos visto, el urbanismo racionalista en tanto tecnocracia, en su llamada a la eficiencia, zonificará la ciudad. Para ello propondrá eliminar los puntos de contacto entre clases y, por tanto, las interacciones complejas y a menudo imprevisibles. Con esto, se apuesta también por la posibilidad utópica de eliminar el conflicto en la ciudad. Un conflicto que no se toma como un hecho simplemente -y constitutivo por otro lado-, sino que se deriva de una visión de la ciudad putrefacta debido básicamente a la mezcolanza de usos y tipos poblacionales. Estos urbanistas racionalistas tanto como los decimonónicos- odiaban la mezcla, lo imprevisible y luchaban contra "el desorden" que implica la superposición de prácticas y el entrecruzamiento de experiencias. La voluntad de hacer eficiente la ciudad era idéntica a la de purificar la ciudad y, con ello, la sociedad.

La Ville Radíeuse se convertía en el referente para la construcción de las ciudades del futuro. Los proyectos debían partir de cero y obedecer únicamente a "las normas de la armonía estética y la lógica impersonal de la división funcional”. (Bauman, 2001, pp. 56-58). En estos momentos, efectivamente, se tenía una fe absoluta en que "El 'Plan' (por ser producto de la razón impersonal, no de la imaginación individual por brillante o profunda que ésta sea) es la condición única [...] de la felicidad humana, que no puede basarse sino en la perfecta articulación de necesidades humanas definidas científicamente y la disposición unívoca, transparente y legible del espacio vital". (ibidem). Desde Max Weber (1968[1919]) sabemos que la modernidad es experta en la creación de oposiciones: Razón/pasión, regular/irregular, orden/desorden. Crea distinciones para ordenar y clasificar, diferenciar y definir. La modernidad problematiza conceptos y personas. Las ideologías del urbanismo y del civismo en Barcelona han sido tecnologías de poder al servicio de esta manera dicotómica y perversa de afrontar los "problemas sociales" que, paradojalmente, los multiplica y agrava.

ACE, 15 (45) CC BY-ND 3.0 ES | UPC Barcelona, España | Arqueología del futuro en el barrio de El Raval de Barcelona. A propósito de tres inercias del urbanismo tecnocrático y sus efectos indeseables. DOI http://dx.doi.org/10.5821/ace.15.45.10311 
Respecto al urbanismo, y como acabamos de ver en los apartados anteriores, desde Cerdà existía un plan de apertura en canal de lo que posteriormente sería el Distrito № o Raval. Para los responsables de la última gran intervención analizada en El Raval, la Illa Robador, esta "cloaca de miseria" (Bohigas, 2005) no necesita ninguna otra intervención pública que no sea policial y/o urbanística, recordemos, "relegando a un segundo plano el trabajo social" (Bohigas et al., 2002).

En la actualidad estas tecnologías abrían mutado del urbanismo al civismo. Se trata de una normativización intensiva del comportamiento en el espacio público. Elocuentemente, establece una relación directa con la biopolítica cuando un conocido sociólogo catalán afirma que "un incívico es un desequilibrado social por muy buena persona que sea” (Cardús, 2003). Esta forma patologizante y agresiva de percibir, comprender y resolver los "problemas sociales" de El Raval parece haber sido hegemónica durante décadas entre sociólogos, urbanistas y técnicos o responsables políticos.

El civismo, inspirado en las doctrinas neoyorquinas de Zero Tolerance y que se inician con el siglo XXI en Barcelona, han supuesto que, tanto en El Raval (Lundsteen y Fernández, 2020) como en la mayoría de grandes ciudades norteamericanas y europeas, la ambigüedad sea sinónimo de desorden y, por tanto, se le considere inaceptable (De Giorgi, 2000; Stuart, 2015). Producto de estas medidas, se han multiplicado los "comportamientos antisociales" en detrimento de los delitos (Mooney y Young, 2016). Estos comportamientos "desordenados", por minúsculos que sean, deberían atajarse contundentemente mediante la prevención, disuasión o represión, con la improbada tesis que así se "reducirá la gran criminalidad" (Greene, 2014).

Para nuestro caso de estudio, desde 2003 arranca una campaña político-mediática inspirada en esta doctrina (Silveira, 2006) que acabará a finales del 2005 con la aprobación de la controvertida normativa del civismo. El alcalde Joan Clos anunciaba que, comportamientos "como pernoctar en las aceras y ensuciarlas" se pueden considerar atentados contra la paz social y que por eso será "más severa, estricta y contundente [...] Habrá más detenciones y más persecución [transformando] algunas faltas [en] delito" (Muñoz, 2005). Huelga decir que este orden se fundamenta en la represión y la violencia policial; es por eso por lo que podemos entender la violencia institucional desplegada en El Raval desde épocas postfranquistas como "el producto residual de la fábrica del orden" (Bauman, 2004, p. 20).

Una vez que la primera inercia registrada, la que es producto de la biopolítica, permite categorizar un segmento poblacional de El Raval como incívico, puede convertirse fácilmente en anormal, molesto, prescindible o expulsable. Cuando esto sucede, es necesario, con las mejores intenciones, solucionar los "problemas sociales" causados -o como consecuencia- de este segmento poblacional. Se trata de la imperiosa necesidad -racional, instrumental, puramente moderna- de acabar con -o en la versión actuarial (De Giorgi, 2000) disminuir- los riesgos a partir de "la ingeniería social". Ésta conlleva que para ver aplicado sus ingenios, se reproduzcan e incluso inventen "problemas sociales". Por ejemplo, los ya mencionados "problemas de incivismo" o el más reciente de los "narcopisos" son, no hace falta decirlo, problemas resultantes de una concepción sesgada de lo que debe ser un barrio caracterizado por la densidad, la pobreza y las formas alternativas de procurarse la subsistencia.

Estos procesos suponen profundizar en la lógica adiafòrica ${ }^{21}$ propia de toda estructura social moderna o burocrática. Este razonamiento característico de las racionalidades instrumentales, denunciadas en el siglo pasado por la primera Escuela de Frankfurt, implica "convertir ciertas acciones y ciertos objetos de una acción, en moralmente neutras o irrelevantes exentos de la categoría de fenómenos

\footnotetext{
${ }^{21}$ Los procesos de adiaforización (la separación de la ejecución de un acto y su valoración moral) o de indiferencia moral que son típicos de la modernidad, requieren el establecimiento de distancias entre los elaboradores de la norma coactiva y moralmente reprobable y la ejecución de esta. Esta lógica adiafórica es desglosada con extrema precisión al descubrir hasta qué punto el Holocausto puede haber devenido máxima expresión de la modernidad, de su rostro más tenebroso y vigente (Bauman, 2006).
}

ACE, 15 (4.5) CC BY-ND 3.0 ES | UPC Barcelona, España | Arqueología del futuro en el barrio de El Raval de Barcelona. A propósito de tres inercias del urbanismo tecnocrático y sus efectos indeseables. DOI http://dx.doi.org/10.5821/ace.15.45.10311 
susceptibles de una evaluación moral” (Bauman, 2004, p. 25). Este proceso estaría llevando la adiaforización de la sociabilidad humana "hacia unas profundidades que aún quedan por descubrir" (Bauman, 2006, p. 254).

Celosa y fatalmente, parecería que ciudades como Barcelona se habrían doblegado al dominio incuestionado de unas tecnologías, tanto financieras como de control urbano, que progresivamente van borrando el rostro humano de los segmentos más descapitalizados, no sólo de El Raval sino de toda la ciudad.

Tal como se está mostrando, se trata de la concreción de un giro hacia el trato de los gobernados que tiene sus principios eugenésicos, practicados por primera vez de forma masiva, en los campos de concentración nazi (Bauman, 2006). Y aunque esto pueda parecer muy severo, sólo hay que recordar que la idea gerencial de la sociedad como si fuera una empresa ocupada simple y exclusivamente en la producción de beneficios por oligopolios, convierte esta población en "signos hexagonales [para ser] zarandeada, expropiada y desarraigada como si sobre ella se hubiera abatido una potencia conquistadora" (Jacobs, 2011, p. 30). En el caso de El Raval, durante el período posfranquista o democrático estudiado (1988- 2014), se ha segregado y jerarquizado sus practicantes y habitantes en función de su adecuación estética (apariencia), estilística (como sujeto de producción, pero sobre todo de consumo) y ética (solícitos, obedientes).

\subsection{La forzada e imposible homologación entre espacio doméstico y vida pública}

La taylorización de Barcelona (Roca, 1998) y su zonificación en áreas industriales, residenciales o de ocio que propugnaba la "arquitectura moderna”, conlleva lógicamente la expulsión de población y el reordenamiento de las actividades económicas. En nuestro caso y según describe acertadamente José Luís Oyón, ha sido un elemento decisivo en lo que él ha llamado "la quiebra de la ciudad popular" (2008) y, por otro lado, en lo que Richard Sennett apuntaba como "el declive del hombre público" (1978). Para el sociólogo chicagano, la segregación de actividades laborales, educativas, de ocio, familiares y comerciales es uno de los motivos que medra al hombre público. Lo inhibe del trato con extraños, así como de la cultura urbana, la de la calle, recluyéndolo paulatinamente en el ambiente íntimo o privado. Esta retirada, entre otras consecuencias, produce "analfabetos urbanos", es decir, personas que poco a poco tienen más dificultades para incorporarse o relacionarse en espacios urbanos típicamente densos en términos de alteridad. Es en este sentido que la calle, repleta de extraños, se convierte progresivamente en un entorno hostil sobre el que es urgente y necesario intervenir.

El Raval -quizás el espacio de Barcelona donde queda mejor reflejada la definición simmeliana de ciudad como lugar donde se intensifica la vida nerviosa (1908 [1986])- vive en constante tensión dialéctica contra los intentos colonizadores del Sistema (Habermas, 1981). Y esto se ha hecho inercialmente para satisfacer no sólo intereses privados internacionales y ligados a oligopolios, sino también como un efecto de un momento clave de adolescentitzación de la sociedad.

Sennett nos recuerda que desde mediados del siglo XIX la familia pasa a ser el patrón con el que medir las relaciones en público. Se consideró la vida pública como moralmente inferior. Estabilidad e intimidad estaban ligadas a la familia. Bajo este marco ideal, la legitimidad del orden público se puso en entredicho. Partiendo de la idea de la Ilustración, según la cual, en público todo el mundo tenía que ser igual, se elaboró un cuadro normativo que comportaba una severa represión de la diferencia ya que "si los hombres debían convencer de su dignidad colectiva a través de sus similitudes, los que destacaban, ponían en cuestión esta comunidad”. Lo importante entonces es que no haya ningún otro fuera del círculo íntimo que nos acabe importando (Sennett, 1975, p. 62).

ACE, 15 (4.5) CC BY-ND 3.0 ES | UPC Barcelona, España | Arqueología del futuro en el barrio de El Raval de Barcelona. A propósito de tres inercias del urbanismo tecnocrático y sus efectos indeseables. DOI: http://dx.doi.org/10.5821/ace.15.45.10311 
Así pues, la vida pública se habría convertido en incivilizada en la medida que se ha impuesto esta retrotracción a la intimidad familiar y el consiguiente rechazo a la vida pública. Paradójicamente, el no entregarse al mar de imprevisibilidades idiosincrático de barrios como El Raval o el regatear la confianza respecto al otro, ha producido las condiciones de posibilidad para poner en marcha estrategias que aspiran a sosegar taxativamente esta nerviosidad y conflictividad.

"Nosotros nos quejamos de todo el movimiento que hay. Yo venía buscando diversidad y singularidad. A mí, antes, el Rawal Super me encantaba, pero ahora estamos desbordados por este tipo de tiendas y no hay nada más. Bueno, es que esto es Karachi directamente. [...]no puedes circular a ninguna hora porque siempre está degradado, porque visualmente ya es problemático. [...] las prostitutas incluso terminan saludándote [...] y los domingos que paseo con mi nieto [debo esquivarlas] para que no piensen que somos amigos. 22 "

Esta imagen del espacio público como un campo de batalla convierte toda expresión de alteridad mal templada en "atentados contra la convivencia" -según la expresión del entonces alcalde Jordi Hereu (2009). Es en estos términos que Sennett plantea la noción de una sociedad incivil que rechaza el juego y la distancia entre la personalidad íntima y la que está en público. La civilidad es "la actividad que protege a la gente entre sí y, en cambio, les permite disfrutar de la compañía de los demás. Llevar una máscara constituye la esencia de la civilidad" (Sennett, 1978, p. 578). Civilidad para Sennett "significa tratar a otros como si fueran extraños y forjar un vínculo social sobre esta distancia social" (ibidem) y aquí, la ciudad es el lugar primordial para este contacto entre extraños. Se manifiesta así la incivilidad de barrios como El Raval rechazando cualquier forma de incomodidad. Incomodidades que, tal y como se apuntaba renglones arriba, no dejan de multiplicarse exponencialmente y de forma paralela a las normativizaciones restrictivas y agresivas de la vida pública de lugares como El Raval.

El último ejemplo lo encontramos en la analogía establecida entre civismo y patriotismo. Se trataría de la última forma de exclusión, que añade a los criterios tecnocráticos uno de emotivo, la adscripción nacional. La afirmación según la cual el "civismo es patriotismo" (Cardús, 2006, p. 102), tiene la dudosa virtud de excluir en dos direcciones: los no naturales han de mostrar su aprecio a la patria ejerciendo de modelos cívicos, serenos e inmaculados mientras que los naturales que no se comporten adecuadamente se extranjerizan y pasan a ser señalados como ciudadanos de segunda, justamente lo que son los "extranjeros" o "inmigrantes" por definición, una manifestación de alteridad radical inasumible. En este sentido, una opinión coincidente entre los nuevos vecinos de la calle d’En Robador y los policías entrevistados en 2011 era que: la única manera de solucionar el problema de incivismo de El Raval es derribar los pisos antiguos de Robador, endurecer la ley de extranjería y el Código Penal (Fernández, 2014).

Esta actitud de recelo ha convertido a los habitantes de las grandes ciudades en temerosos peatones sometidos a los vaporosos y fantasmagóricos datos de aumento de la sensación de inseguridad. Al pretender eliminar lo impredecible de un espacio urbano como El Raval-cuando sabemos que es su característica constitutiva -se ha ido configurando una identidad urbana que es paradójicamente antiurbana, llamada cívica pero que en realidad es su más perverso reverso: una intolerancia selectiva que convierte un número creciente de comportamientos en el espacio público en expresiones de alteridad radical y categorías humanas descapitalizadas en indeseables sobre -y contra- las que "debe hacerse alguna cosa".

\footnotetext{
22 Testigos de vecinos aparecidos consecutivamente en programa de la televisión nacional TVC, Els Matins titulado "Marxar de El Raval" y "Els veïns de El Raval, tips de la inseguretat al barri”, ambos de 2010 y el último en una entrevista colectiva con los nuevos vecinos de Robador en 2011
}

ACE, 15 (45) CC BY-ND 3.0 ES | UPC Barcelona, España | Arqueología del futuro en el barrio de El Raval de Barcelona. A propósito de tres inercias del urbanismo tecnocrático y sus efectos indeseables. DOI http://dx.doi.org/10.5821/ace.15.45.10311 


\section{Conclusiones. La posibilidad de una esperanza}

"Si según muestra la razón analítica el mundo no es más que una máquina que funciona autónomamente, si el ser humano no es esencialmente diferente del resto de las estructuras moleculares y el cosmos entero no es más que un juego sin sentido entre combinaciones de átomos, ¿sobre qué podría basarse un orden moral? ¿sobre qué base los individuos aislados entre sí por sus luchas de supervivencia y sus egoísmos pueden llevar a cabo su articulación social, esa solidaridad que hace de ellos una comunidad? Uno de los problemas importantes del pensamiento político del siglo XIX [...], es el de la brecha abierta entre los ciudadanos y el Estado que deja al descubierto la falta de legitimidad propia de las sociedades modernas. El problema es encontrar el modo para que de nuevo una comunidad pueda funcionar como una asociación solidaria de ciudadanos cuyo común acuerdo no solo se debe el factor externo y coactivo del control represivo del Estado." (Sánchez Meca, 2013 pp. 177)

Los recientes cambios en la calle d'En Robador no dejan de asombrarnos. En 2014 se favoreció la instalación de terrazas de bares, básicamente en la plaza Salvador Seguí, y se inauguró un "gastrobar", La Robadora, que se anunciaba de la siguiente manera: "El próximo jueves 13 de noviembre a las 19.30h se abrirán las puertas del Gastrobar LA ROBADORA ubicado en medio de El Raval. Nos encontramos en una de las calles más underground, secretas, frecuentadas y diversas de la ciudad. Un verdadero referente histórico de la Barcelona más canalla: Robadors".

También en 2014 nos resultó muy elocuente la situación que vivimos frente al desaparecido Bar Alegría, un tradicional local de alterne reconvertido en galería de arte y agencia inmobiliaria, cuando detenidos frente al local, brotó del interior de la inmobiliaria un hombre interpelándonos con acento italiano y de edad madura. Nos preguntaba si estábamos interesados en vivir allí; les dijimos que sí, pero que -haciendo un papel de agente doble o espía- nos preguntábamos como íbamos a vivir allí cuando, en el mismo momento que manteníamos nuestra conversación, la calle estaba en plena ebullición de un viernes tarde, repleta de prostitutas, dealers y consumidores de drogas. Su respuesta nos dejó estupefactos: "esta calle, Robadors, va a ser la nueva mina de oro de Barcelona".

Seis años después, aún con la crisis provocada por la pandemia del COVID19, una vez reabiertos los bares y restaurantes, la calle d'En Robador y alrededores, mantienen la vitalidad de siempre. A diferencia de gran parte del distrito de Ciutat Vella que, con la caída del turismo, parece haberse vaciado. Se han abierto nuevos locales de telefonía, de alimentación y un nuevo restaurante tipo fastfood.

Llegados a ese punto, sostenemos que, desde esta forma de concebir el urbanismo, se ha abordado el alambicado arte de vivir en sociedad mediante fórmulas cartesianas, a veces maniqueas y, a menudo, elitistas. Sirva para comprender lo que decimos, la velada crítica que Manuel Vázquez Montalban vertió sobre los planes del GATCPAC: "Ni siquiera puede ofrecerse el referente real de la ciudad socialista, lo que pudo haber sido y no fue, porque finalmente también se vio condicionada por ideologizaciones de la élite, por la desigualdad de uso al servicio de la élite y por la estética de la élite del poder." (1993a, p. 110)

Hemos advertido, después de años de investigación, que estos urbanismos no sólo avanzaban y señalaban cómo debían ser las ciudades del futuro en "un plano literalmente ideal" sino que ellas mismas eran producto preferente y herramienta fundamental de unas formulaciones del poder principalmente impulsadas por la fiebre del lucro y de la distinción.

Hemos mostrado que las grandes dificultades que señala acertadamente Montalbán han persistido en los planes e intervenciones del periodo postfranquista. En ambos casos, nos encontramos de

ACE, 15 (45) CC BY-ND 3.0 ES | UPC Barcelona, España | Arqueología del futuro en el barrio de El Raval de 20 Barcelona. A propósito de tres inercias del urbanismo tecnocrático y sus efectos indeseables. DOI http://dx.doi.org/10.5821/ace.15.45.10311 
nuevo con la tecnocracia como la gruesa soga negra que une la ciudad lecobursiana entendida como "máquina de habitar", la ciudad taylorista y la Smart City.

Lo que vemos aquí es la remodelación del discurso del poder que tiene su máxima potencia y eficacia precisamente en su capacidad para hacerse invisible. Para ello emplea los juegos de palabras de la supuesta neutralidad de la ciencia, de forma que el último de estos intentos de hacer pasar gatos neoliberales por liebres progresistas, la acríticamente aplaudida por alcaldes de prácticamente todo el espectro político, Smart City, ha refundando la camaleónica habilidad de la tecnocracia para tratar de impedirnos ver la cara más fría y despótica del poder: desacreditar, humillar y enajenar la soberanía popular de su facultad de deliberar y determinar el curso de la ciudad. Y todo esto hacerlo en nombre del gobierno -ya no de los técnicos, arquitectos, urbanistas o ingenieros- sino de la tecnología y los ingenios.

A nuestro entender, la crítica al urbanismo tecnocrático aquí expuesta, así como su función de propulsor de las tres inercias glosadas, han acabado determinando su tarea y ha condicionado -y a veces invertido- su voluntad de "mejorar, sanear, rehabilitar o recuperar" El Raval. Estamos plenamente convencidos de que identificar y negociar estas inercias, permitirían redirigir la práctica urbanística hacia el proyecto Ilustrado, o en palabras más modestas, consolidar ciudades más solidarias, autónomas e igualitarias, aunque quizás, no tan "Smart".

\section{Agradecimientos}

Queremos mostrar nuestro agradecimiento al Catedrático de la UPC Josep Muntañola por su invitación a presentar los avances nuestra investigación en el 17ํㅡ Congreso ARQUITECTONICS Mind, Land \& Society en mayo de 2019, producto de la cual es este artículo. Queremos agradecer a Juan José Lahuerta profesor de Historia de la ETSAB facilitarnos dos de sus textos más inaccesibles y destacados sobre la estética de los bombardeos. También queremos agradecer a Rolando Biere, Arquitecto, Investigador CPSV-UPC por invitarnos a presentar una versión mejorada y ampliada de nuestro trabajo en el Congreso CTV, Barcelona 2019. Finalmente, queremos agradecer a los revisores del artículo sus oportunos comentarios que han mejorado substancialmente la versión final del mismo.

\section{Autoría}

El primer autor es el responsable de la investigación, el análisis de los datos y la redacción del apartado quinto. La segunda autora ha elaborado el cuarto apartado. La introducción, el tercer apartado y las conclusiones son fruto del trabajo conjunto de ambos autores.

Conflicto de intereses: Los autores declaran que no hay conflicto de intereses.

\section{Bibliografía}

Abella, M. (2004). Ciutat Vella: el centre històric reviscolat. Barcelona, España: Aula Barcelona.

Adorno, T., \& Horkheimer, M. (2008 [1944]). Prólogo [1944 y 1947]. En Dialéctica de la ilustración. Fragmentos filosóficos. pp. 51-58. Madrid, España: Trotta. C.

Agamben, G. (2010). Homo sacer. 1. El poder soberano y la nuda vida. València: Pre-Textos.

ACE, 15 (4.5) CC BY-ND 3.0 ES | UPC Barcelona, España | Arqueología del futuro en el barrio de El Raval de Barcelona. A propósito de tres inercias del urbanismo tecnocrático y sus efectos indeseables. DOI http://dx.doi.org/10.5821/ace.15.45.10311 
Aisa, F., \& Vidal, M. M. (2006). El Raval :un espai al marge. Barcelona, España: Base.

Albertí, S., \& Albertí, E. (2004). Perill de bombardeig. Barcelona sota les bombes (1936-1939). Barcelona, España: Albertí Editor.

Arendt, H. (1967). Eichmann en Jerusalén: un estudio sobre la banalidad del mal (1999. a ed.). Barcelona, España: Lumen.

Ares, Ó. (2010). Sert, Le Corbusier y el Plan Macià: heterodoxia y contradicciones formales. DC. Revista de Crítica Arquitectónica, 19-20, 173-182. http://hdl.handle.net/2099/10606

Bauman, Z. (2006). Modernidad y holocausto Madrid, España: Sequitur.

Bauman, Z. (2001). Guerras por el espacio. Informe de una carrera. En La globalización. Consecuencias humanas (Vol. 52, pp. 39-73). México D.F., México: Fondo de Cultura Económica México.

Bauman, Z. (2004). El eterno retorno de la violencia. En J. Beriain (Ed.), Modernidad y violencia colectiva (pp. 17-48). Madrid, España: Centro Investigaciones Sociológicas.

Bauman, Z. (2006). Modernidad y holocausto (3a ed.). Sequitur. Madrid, España.

Bauman, Z., \& Tabet, S. (2017). Del proyecto moderno al mundo líquido. Conversación con Zygmunt Bauman. Revista Mexicana de Ciencias Politicas y Sociales, 62(230), 287-303. DOI: https://doi.org/10.1016/S0185-1918(17)30025-9

Benévolo, L. (1993). La ciudad europea. Barcelona, España: Crítica.

Benjamin, W. (2015[ 1928]). Calle de sentido único. Madrid: Akal.

Benjamin, W. (2008). Tesis sobre la historia y otros fragmentos. México D.F., México: Editorial ItacaUniversidad Autónoma de la Ciudad de México.

Benvenuty, L. (2009). La maldición del Raval. La Vanguardia.

Bergalli, R., \& Capel, H. (1990). Los Espacios acotados :geografía y dominación social. Barcelona, España: Promociones Publicaciones Universitarias.

Bohigas, O. (1960). Homenaje al G.A.T.C.P.A.C. Cuadernos de arquitectura, 40, 43-45. https://www.raco.cat/index.php/CuadernosArquitectura/article/view/109508

Bohigas, O. (1986). Reconstrucción de Barcelona. Madrid, España: Ministerio de Obras Públicas y Urbanismo. Secretaría General Técnica.

Bohigas, O. (2005). Cloaca de Miseria. El País.

Bohigas, O. (2010). Pròleg. En Gil i Tort \& Domènech (Eds.), Un nou model d'arquitectura al servei d'una idea de país (2013. a ed.). Barcelona, España: Fundació Josep Irla. https://irla.cat/wpcontent/uploads/2015/10/arquitectura_set2013.pdf

Bohigas, O., Ferrer, J., \& Sust, X. (2002). Rambla del Raval, Barcelona. Ficha resumen de rehabilitación urbana: EFU22.

ACE, 15 (4.5) CC BY-ND 3.0 ES | UPC Barcelona, España | Arqueología del futuro en el barrio de El Raval de 22 Barcelona. A propósito de tres inercias del urbanismo tecnocrático y sus efectos indeseables. DOI http://dx.doi.org/10.5821/ace.15.45.10311 
Bourdieu, P. (2008). Una ciencia que incomoda. En Cuestiones de Sociología (pp. 20-37). Madrid: Akal. Cadenas Álvarez, M. (2018). El urbanismo del mientras tanto. Primeras notas etnográficas sobre prácticas de construcción colaborativa en tiempos de "crisis". En DDAA (Ed.), Mierda de ciudad Una rearticulación crítica del urbanismoneoliberal desde las ciencias sociales (pp. 168-184). Barcelona, España: Pol·len Edicions.

Cadenas Álvarez, M., \& Fernández González, M. (2018). La revolució Urbana. Entre la municipalització i la collectivització de la propietat inmmobiliària a Barcelona, 1936-1937. Revista Masala, 76, 24-29. https://masala.cat/la-revolucio-urbana/

Campillo, A. (1999). Cuatro tesis para una teoría de la historia. En El gran expermiento. Ensayos sobre la sociedad global (pp. 43-73). Madrid, España: Catarata.

Cardús, S. (2003). "Un incívico es un desequilibrado social, por buena persona que sea”. La Vanguardia, p. 6.

Cardús, S. (2006). L'educació del civisme. De la retòrica dels valors a la bona organització. En Diàlegs interiors (pp. 79-122). Barcelona: Departament d'Interior.

Castel, R. (1983). De la dangerosité au risque. Actes de la recherche en sciences sociales, 47(1), 119-127. DOI: https://doi.org/10.3406/arss.1983.2192

Castoriadis, C. (1987). The Imaginary institution of society. Cambridge, England: Polity Press.

Cerdà, I. (1978[1867]). Monografía estadística de la Clase obrera de Barcelona en 1856. En Teoría general de la urbanización y aplicación de sus principios y doctrinas a la reforma y ensanche de Barcelona (1978. ${ }^{a}$ ed.). Madrid, España: Instituto de Estudios Fiscales.

Cohen, S. (2002). Folk devils and moral panics :the creation of the mods and rockers (Vol. 3). London, England: Routledge.

Colom, R. (2005). "Del Xino al Raval". Programa Millenium, de Televisió de Catalunya. Televisió de Catalunya.

De Giorgi, A. (2000). Control Actuarial y transformación social. Lineamientos para una posible crítica. En Tolerancia Cero. Estrategias y prácticas de control (pp. 125-171). Barcelona: Virus editorial.

De Otero, L. (1943). Reformas de urbanización en Barcelona. A la mayor brevedad se va a poner en práctica la demolición del llamado"Barrio chino". Boletín de la propiedad privada, 4(1), 0-1.

Ealham, C. (2005). Class, Culture and Conflict in Barcelona, 1898-1937. London, England: Routledge.

Fernández González, M. (2012). Contra el bé, la civilització i el progrés Apunts per una epistemologia de la moral relativa a les intervencions urbanístiques al Raval. Astrolabio: Revista Internacional de Filosofia, 13, 156-164. https://www.raco.cat/index.php/Astrolabio/article/view/256285

Fernández González, M. (2014). Matar al Chino. Entre la revolución urbanística y el asedio urbano en el barrio del Raval de Barcelona. Barcelona, España: Virus Editorial.

Fernández, M. (2014). La desilusión de las 'smart cities'. Está sucediendo, pero no, pero no en la forma en la nos lo han contado. Revista Papers, 57(Discursos emergentes para un nuevo urbanismo), 105141.

ACE, 15 (4.5) CC BY-ND 3.0 ES | UPC Barcelona, España | Arqueología del futuro en el barrio de El Raval de Barcelona. A propósito de tres inercias del urbanismo tecnocrático y sus efectos indeseables. DOI http://dx.doi.org/10.5821/ace.15.45.10311 
Foucault, M. (1976). Del poder de soberanía al poder sobre la vida. Dejar morir y hacer vivir. En Genealogía del racismo. De la guerras del racismo al racismo de Estado (pp. 193-214). Madrid, España: Ediciones la Piqueta.

Foucault, M. (1978). Los medios del buen encauzamiento. En Vigilar y castigar (pp. 175-198). Madrid, España: Siglo XXI.

Fraile, P. (1990). Lograr obediencias maquinales. Un proyecto espacial. En Los Espacios acotados: geografía y dominación social (pp. 13-39). Barcelona, España: Promociones Publicaciones Universitarias.

Fraile, P. (2003). La organización del espacio y el control de los individuos. En R. Bergalli (Ed.), Sistema penal y problemas sociales (pp. 169-). Valencia, España: Tirant lo Blanch.

Fraile, P. (2005). El vigilante de la atalaya: la génesis de los espacios de control en los albores del capitalismo. En Minor (Vol. 11). Lleida, España: Milenio.

GATCPAC. (1932). El Barrio Chino de Barcelona (Distrito V). A. C. Documentos de Actividad Contemporánea, 6, 31-33. https://issuu.com/faximil/docs/1932-ac-06

GATCPAC. (1937). Esbós del pla a seguir per una acció immediata en el problema de la vivenda al casc antic de la ciutat. A.C. Documentos de Actividad Contemporánea, 25, 29. https://issuu.com/faximil/docs/1937-ac-25/15

Granell Trias, E. (1997). UNA casa: Un árbol. En Le Corbusier y España (pp. 109-120). Barcelona, España: Centre de Cultura Contemporània de Barcelona.

Grau, R., \& López, M. (1988a). Cara y cruz del Urbanismo de Cerdà. En R. Grau (Ed.), Exposición Universal de Barcelona :libro del centenario, 1888-1988 (pp. 166-187). Barcelona, España: Comisión Ciudadana para la Conmemoración del Centenario de la Exposición Universal de Barcelona del Año 1888.

Grau, R., \& López, M. (1988b). Las batallas por el ensanche. En R. Grau (Ed.), Exposición Universal de Barcelona :libro del centenario, 1888-1988 (pp. 191-225). Barcelona, España: Comisión Ciudadana para la Conmemoración del Centenario de la Exposición Universal de Barcelona del Año 1888.

Greene, J. R. (2014). Zero tolerance and policing. En M. D. Reisig \& R. J. Kane (Eds.), The Oxford Handbook of Police and Policing (pp. 1-30). Oxford, England: Oxford University Press.

Guàrdia Bassols, M. (2009). La ciutat del XIX i el pensament modern. Metropolis. Revista d'informació i pensament urbà, 76(La raó de la ciutat: el Pla Cerdà), 58-61. https://bcnroc.ajuntament.barcelona.cat/jspui/handle/11703/93395

Guicheteau, G. (1973). Marseille 1943, la fin du Vieux-Port. Marseille, France: Éditions Le Provençal.

Habermas, J. (1981). Historia y crítica de la opinión pública: la transformación estructural de la vida pública. México, D.F. etc: Gustavo Gili.

Hall, P. (2002). Cities of tomorrow: an intellectual history of urban planning and design in the twentieth century (3rd ed.). Malden [etc.]. Nova Jersey, USA: Blackwell Publishers. Hoboken.

Halpern, O., Lecavalier, J., Calvillo, N., \& Pietsch, W. (2013). Test- Bed Urbanism. Public Culture, 25(2), 272-306. https://read.dukeupress.edu/public-culture/article-abstract/25/2\%2070/272/85758/TestBed-Urbanism?redirectedFrom=fulltext

ACE, 15 (4.5) CC BY-ND 3.0 ES | UPC Barcelona, España | Arqueología del futuro en el barrio de El Raval de Barcelona. A propósito de tres inercias del urbanismo tecnocrático y sus efectos indeseables. DOI http://dx.doi.org/10.5821/ace.15.45.10311 
Harvey, D. (2008). París, capital de la modernidad. Tres Cantos, Madrid, España: Akal.

Hereu, J. (2009). En defensa del Raval. El País, p. 31.

Heynen, H. (1999). Architecture and Modernity. A Critique. Cambridge, Massachusetts; London, England: Massachusetts Institute of Technology. DOI: https://doi.org/10.4324/9781315262239

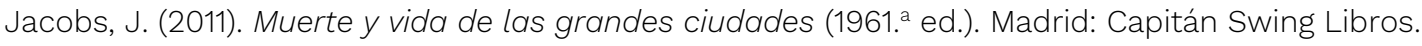

Kuhn, T. S. (1971). La Estructura de las revoluciones científicas. México, D.F., México: F.C.E.

Lahuerta, J. J. (2012). Estética de los bombardeos. En La Fabrica (Ed.), Encuentros con los años 30 (pp. 321-329). Barcelona: Museo Nacional Centro de Arte Reina Sofía.

Le Corbusier. (1923). Arquitectura o revolución. En Hacia una arquitectura (1978. a ed., pp. 228-243). L'Hospitalet de Llobregat, España: Editorial Poseidon.

Le Corbusier. (1924). La ciudad del futuro (1962.. ed.). Buenos Aires, Argentina: Ediciones Infinito.

Le Corbusier. (1934). The radiant city: elements of a doctrine of urbanism to be used as the basis of

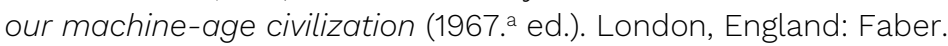

Le Corbusier. (1935). Aircraft (1985. ${ }^{a}$ ed.). London, England: Trefoil Publications Ltd.

Lévi-Strauss, C. (1960). L’Anthropologie sociale devant l'Histoire. Annales. Economies, sociétés, civilisations, 15(04), 625-637. DOI: https://doi.org/10.3406/ahess.1960.421640

López Villanueva, C., \& Alabart Vilà, A. (2011). Dinámicas urbanísticas y socioeconómicas en ciutat vella. Architecture, City and Environment, 6(17), 157-186. DOI: http://dx.doi.org/10.5821/ace.v6i17.2533

Lundsteen, M., \& Fernández González, M. (2020). Zero-Tolerance in Catalonia: Policing the Other in Public Space. Critical Criminology. DOI: https://doi.org/10.1007/s10612-020-09533-1

Madrid, F. (1925). Los bajos fondos de Barcelona. El Escándalo, 1(Octubre), 4-5.

Mallarach, J. (1999). PERILL al centre històric de Barcelona. [Enregistrament en vídeo]. RTVE.

Mauss, M. (1995 [1936]). Sociologie et anthropologie.. Paris, France: Presses universitaires de France. Mcdonogh, G. W. (1987). The Geography of Evil: Barcelona's "Barrio Chino". Anthropological Quarterly, 60:4(Oct), 174-184.

Mooney, J., \& Young, J. (2016). The decline in crime and the rise of anti-social behaviour: Probation Journal, 53(4), 397-407. DOI: https://doi.org/10.1177/0264550506069364

Muñoz, O. (2005). Vía penal contra el incivismo. La Vanguardia.

Oyón, J. L. (2008). La quiebra de la ciudad popular. Espacio urbano, inmigración y anarquismo en la Barcelona de entreguerras, 1914-1936. Barcelona: Serbal.

Paquer, A. (1962). Historia del barrio Chino de Barcelona. Barcelona, España: Rodegar.

Pascual Esteve, J. M. (1981). Informe sociológico del Distrito V. En Serveis socials. Barcelona, España:

ACE, 15 (4.5) CC BY-ND 3.0 ES | UPC Barcelona, España | Arqueología del futuro en el barrio de El Raval de 25 Barcelona. A propósito de tres inercias del urbanismo tecnocrático y sus efectos indeseables. DOI: http://dx.doi.org/10.5821/ace.15.45.10311 
Ajuntament de Barcelona, Àrea de Serveis Socials, Consell Municipal del Districte V.

Perelman, M. (2018). Le Corbusier una fría visión del mundo. Barcelona, España: Virus editorial.

Pérez, B. (2017, septiembre 9). El horror de convivir con los narcopisos. El Periódico de Catalunya.

Pijoan, J. (1905). La reforma d'en Jaussely: la ciutat ideal. La veu de Catalunya, Any XV núm. 2348. 12 d'octubre.

Puigvert, A. (2005, septiembre 12). El cisne ya no canta. La Vanguardia.

Radcliffe-Brown, A. R. (Alfred R. (1974 [1935]). Estructura y función en la sociedad primitiva (1974. a ed.). Barcelona, España: Ediciones Península.

Roca, F. (1998). La ciutat tayloritzada i la seva crítica. En J. L. Oyón (Ed.), Vida obrera en la Barcelona de entreguerras, 1918-1936 (pp. 203-215). Barcelona: Centre de Cultura Contemporània de Barcelona.

Rufián Roto, R. (2011). Un caso paradigmático: la rehabilitación de las calles d'en Robador y Sant Ramon del barrio del Raval de Barcelona. El oscuro antecedente de la Isla Negra. Sin Permiso.

Sánchez Meca, D. (2013). Modernidad y romanticismo : para una genealogía de la actualidad / Diego Sánchez Meca. Madrid, España: Tecnos.

Sauquet Llonch, R. J. (2014). Existe un urbanismo del gatcpac sin le corbusier? Revista Proyecto, Progreso, Arquitectura, (11), 16-25. DOI: https://doi.org/10.12795/ppa.2014.i11.01

Scott, J. C. (1998a). Authoritarian High Modernism. En Seeing like a state: How certain schemes to improve the human condition have failed (pp. 87-102). New Haven, Connecticut, EEUU: Yale University Press.

Scott, J. C. (1998b). The High-Modernist City: An Experiment and a Critique. En Seeing like a state: How certain schemes to improve the human condition have failed (pp. 103-132). New Haven, Connecticut, EEUU: Yale University Press.

Sennett, R. (1975). Vida urbana e identidad personal. Los usos del desorden. Barcelona, España: Península.

Sennett, R. (1978). El declive del hombre público. Barcelona: Ediciones Península.

Sève, B., \& Redondo, E. (2020). El pabellón de deseos: co-creación y co-instalación artística para la mejora del espacio público. Architecture, City and Environment, 14(42), 8200. DOI: https://doi.org/10.5821/ace.14.42.8200

Shelton, T., Zook, M., \& Wiig, A. (2015). The 'actually existing smart city'. Cambridge Journal of Regions, Economy and Society, 8(1), 13-25. DOI: https://doi.org/10.1093/cjres/rsu026

Silveira Gorski, H. C. (2006). Barcelona y "el fomento de la convivencia" a través de la represión del Espacio público. En R. Bergalli \& I. Rivera Beiras (Eds.), Emergencias urbanas (pp. 239-260). Rubí, España: Anthropos.

Simmel, G. (1986 [1908]). Las grandes urbes y la vida del espíritu. En El individuo y la libertad. Ensayos de crítica de la cultura., pp. 247-262). Barcelona: Península.

ACE, 15 (45) CC BY-ND 3.0 ES | UPC Barcelona, España | Arqueología del futuro en el barrio de El Raval de 26 Barcelona. A propósito de tres inercias del urbanismo tecnocrático y sus efectos indeseables. DOI http://dx.doi.org/10.5821/ace.15.45.10311 
Söderström, O., Paasche, T., \& Klauser, F. (2014). Smart cities as corporate storytelling. City, 18(3), 307320. DOI: https://doi.org/10.1080/13604813.2014.906716

Stolcke, V. (1995). Talking culture: new boundaries, new rhetorics of exclusion in Europe. Current anthropology, 36(1), 1-24. https://www.journals.uchicago.edu/doi/abs/10.1086/204339

Stolcke, V. (2015). A propósito de una Antropología histórica. Número, 20(2), 1-3. https://www.raco.cat/index.php/QuadernselCA/article/view/302781

Stuart, F. (2015). On the Streets, Under Arrest: Policing Homelessness in the 21st Century. Sociology Compass, 911(10). DOI: https://doi.org/10.1111/soc4.12324

Tarragó Cid, S. (1972). El "Plà Macià" o "la nova Barcelona" : 1931-1938. Cuadernos de arquitectura y urbanismo, (90), 24-36. Recuperado de https://www.raco.cat/index.php/CuadernosArquitectura Urbanismo/article/view/111450

Ucelay Da Cal, E. (2000). El maquinista de la generalització que volia salvar el sud. L'Avenç: Revista de història i cultura, 250, 42-49.

Vázquez Montalban, M. (2002). Sobre la deconstrucción de Barcelona. En La Remodelación de Ciutat Vella :un análisis crítico del modelo Barcelona (pp. 6-10). Barcelona, España: Veins En Defensa De Ciutat Vella.

Vázquez Montalbán, M. (1993a). Prólogo. Siempre se espera un verano. En Un verano con mil julios y otras estaciones (pp. 4-18). Barcelona, España: Siglo XXI.

Vázquez Montalbán, M. (1993b, septiembre 14). La limpieza étnica de los señoritos. El País, pp. 1-3.

Villar, P. (1996). Historia y leyenda del Barrio Chino (1900-1992):crónica y documentos de los bajos fondos de Barcelona. Barcelona, España: La Campana.

Villarrolla, J. (1991). Els bombardeigs de Barcelona durant la Guerra Civil (1936-1939). Barcelona, España: Publicacions de l'Abadia de Montserrat.

von Heeren, S. (2002). La Remodelación de Ciutat Vella:un análisis crítico del modelo Barcelona. Barcelona, España: Veïns en Defensa de la Barcelona Vella.

VVAA. (2004). La Barcelona rebelde: guía de una ciudad silenciada (Vol. 14; A. Paz, Ed.). Barcelona, España: Octaedro.

Weber, M. (1919). El político y el científico (1968. ${ }^{a}$ ed.). Madrid, España: Alianza Editorial.

ACE, 15 (4.5) CC BY-ND 3.0 ES | UPC Barcelona, España Arqueología del futuro en el barrio de El Raval de 